\title{
VALORES ORGANIZACIONAIS E DO TRABALHO: \\ um estudo com professores de uma escola filantrópica e confessional de Belo Horizonte (MG)
}

1- Kely Cesar Martins Paiva*

Doutora em Administração pela Universidade Federal de Minas Gerais (UFMG), Brasil.

Professora do Centro de Pós-Graduação e Pesquisas em Administração da Universidade Federal de Minas Gerais (CEPEAD/FACE/UFMG), Brasil.

kelypaiva@face.ufmg.br

http://lattes.cnpq.br/0189644589413057

\section{2- Alexandre Felício Peixoto}

Mestre em Administração pela Faculdade Novos Horizontes (FNH), Brasil.

alxpeixoto@gmail.com

http://lattes.cnpq.br/8641482972300741

\section{3- Talita Ribeiro Luz}

Doutora em Administração pela Universidade Federal de Minas Gerais (UFMG), Brasil.

Professora da Faculdade Novos Horizontes (FNH), Brasil.

talita.luz@unihorizontes.br

http://lattes.cnpq.br/6183564854983291

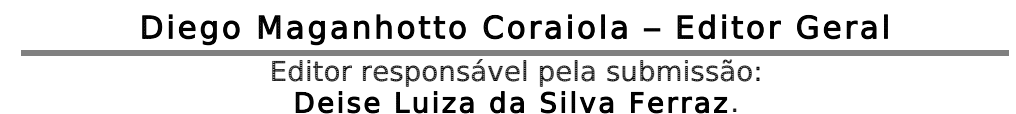

Artigo analisado via processo de revisão duplo cego (Double-blind).

Recebido em: 08/10/2013

Aprovado em: 25/03/2014

última Alteração: 19/03/2014

* Avenida Antônio Carlos, 6627, Prédio FACE, sala 4054. Campus Pampulha, Belo Horizonte - MG, Brasil. CEP: 31270-901. 


\title{
VALORES ORGANIZACIONAIS E DO TRABALHO: UM ESTUDO COM PROFESSORES DE UMA ESCOLA FILANTRÓPICA E CONFESSIONAL DE BELO HORIZONTE (MG)
}

\section{Resumo}

O objetivo deste estudo foi analisar como se encontram configurados os valores organizacionais e do trabalho de professores, na percepção deles próprios. O referencial teórico aprofundou nas temáticas, destacando-se as contribuições de Oliveira e Tamayo (2004) e Porto e Tamayo (2003), cujos modelos conceituais foram adotados para fins da pesquisa realizada. Neste artigo, resultante de uma pesquisa descritiva que contou com uma triangulação metodológica, foi apresentada a parte quantitativa do estudo de caso, que contou com 77 professores de uma instituição de ensino filantrópica e confessional, localizada em Belo Horizonte (MG). Os dados do questionário foram trabalhados com estatística uni e bivariada. Quanto aos valores do trabalho, salientem-se os resultados positivos em relação a "realização", "relações sociais" e "estabilidade"; já o valor "prestígio" foi avaliado mais timidamente pelos pesquisados, o que pode estar refletindo uma precarização do trabalho docente. Quanto aos valores organizacionais, apuraram-se escores positivos no que tange à "autonomia", "realização", "conformidade" e "preocupação com a coletividade". Os testes de comparação apresentaram 6 resultados significativos; já os de correlação somaram 36 resultados significativos (4 entre construtos e dados sociodemográficos; 32 dos construtos entre si). Foram apresentadas as contribuições e limitações do estudo e uma agenda para pesquisas futuras.

\section{Palavras-Chave}

Valores organizacionais; Valores do trabalho; Professor; Instituição privada.

\section{ORGANIZATIONAL VALUES AND WORK VALUES: A STUDY WITH TEACHERS OF A PHILANTHROPIC AND CONFESSIONAL SCHOLL AT BELO HORIZONTE (MG)}

\begin{abstract}
The aim of this study was to analyze how organizational values and work values of teachers are configured, in the perception of themselves. The theoretical deepened the themes, highlighting the contributions of Oliveira and Tamayo (2004) and Porto and Tamayo (2003), whose conceptual models were adopted for purposes of research. In this paper, results from a descriptive research, that included a methodological triangulation, the quantitative part of the case study was presented, which included 77 teachers of a philanthropic and confessional educational institution, located in Belo Horizonte (MG). The questionnaire data were processed with univariate and bivariate statistics. Regarding work values, the positive results emphasize about "achievement", "social relations" and "stability"; the value "prestige" was rated over sheepishly, which may be reflecting a precarious work of those teachers. Regarding organizational values, ascertained scores were positive for "autonomy", "achievement", "conformity" and "concern with the community." Comparison tests showed six significant results, whereas the correlation tests totaled 36 significant results (4 between sociodemographic data and the constructs; 32 between the constructs). Contributions and limitations of the study, as an agenda for future research, were present at the end of the study.
\end{abstract}

\section{Keywords}

Organizational values; work values; teacher; private institution. 
Valores organizacionais e do trabalho: um estudo com professores de uma escola filantrópica e confessional de Belo Horizonte (MG)

\section{Introdução}

A velocidade das inovações e a competitividade do mundo corporativo, a queda de barreiras e fronteiras propiciada pela tecnologia e os avanços logísticos, a busca por margens de lucros cada vez maiores, a luta pelos mercados emergentes, a necessidade de transitar em várias áreas do conhecimento humano por parte dos profissionais dos diversos segmentos e a alta competitividade nos mercados integralmente globalizados são alguns dos fatores que exercem grande impacto sobre a vida dos seres humanos que formam as organizações. Esse ambiente de alta competitividade reflete o cenário para se requerer dos indivíduos o comprometimento organizacional em detrimento dos seus valores pessoais (Tamayo, 2005).

Durante o processo de compreensão das regras para a permanência e o avanço nas na estrutura organizacional, dá-se um confronto vivenciado pelos indivíduos no que tange aos seus valores. Seja no âmbito individual, seja no coletivo, a aceitação ou não das diretrizes apresentadas pelas organizações tende a fomentar incertezas e contrastes quando os indivíduos confrontam seus valores previamente constituídos com os valores do trabalho e com os organizacionais formalmente estabelecidos pelas empresas (Tamayo, 2005).

Note-se que o estudo de valores não está restrito a um grupo de interesse social, econômico ou acadêmico: o ritmo ditado pelas organizações aos indivíduos que as compõem passa naturalmente pelo conjunto de valores e objetivos pessoais desses indivíduos para sua permanência, ou não, nessas organizações (Tamayo, 2005).

O comportamento das pessoas é guiado por seus valores, dentro e fora das organizações. Nesse campo, duas concepções de valores podem pautar as condutas, a saber, os valores organizacionais e os do trabalho. Os valores organizacionais apóiam as atitudes, motivam a construção das metas e objetivos, determinam as formas de julgar a conduta e os acontecimentos organizacionais e orientam a vida da organização. Já os valores do trabalho consistem em princípios ou crenças a respeito das metas ou recompensas desejáveis, hierarquicamente organizadas, conseguidas por meio do trabalho (Ros \& Gouveia, 2006).

A necessidade de adaptação dos indivíduos frente às contingências impostas na vida corporativa, a alta competitividade e as crises econômicas são alguns dos fatores que impõem aos indivíduos e às próprias organizações a necessidade de reverem posicionamentos e, nesse prisma, os valores organizacionais podem constituir uma fonte de segurança ou choque frente à manutenção, ou não, de valores que foram previamente estabelecidos na formação dos indivíduos e das organizações de que fazem parte. Observe-se que esse confronto de valores dinamiza a vida organizacional (Tamayo, 2008).

Este estudo dedicou-se à investigação do tema Valores do Trabalho e Valores Organizacionais, tendo como sujeitos da pesquisa professores. Segundo Tardif (2002), os sistemas escolares vivenciam exigências, expectativas e desafios sem precedentes. Na opinião do autor, recai especificamente sobre os professores um peso maior das mudanças exigidas pelas organizações de ensino. $\mathrm{Na}$ atualidade, as reformas na educação estão diretamente ligadas à formação profissional de professores, à profissionalização da docência e à organização do trabalho do cotidiano dos professores (Tamayo, 2008). Essa nova perspectiva inevitavelmente produz um embate em torno dos valores do trabalho e dos organizacionais.

Diante da importância dos valores no cotidiano das pessoas, no âmbito organizacional e do trabalho e, especificamente, no campo acadêmico, o objetivo geral da pesquisa foi descrever e analisar como se encontram configurados os valores organizacionais e os do trabalho de professores.

Para tanto, optou-se por realizar um estudo de caso em uma Instituição fundada no ano de 1918 e que hoje ocupa importante espaço no cenário da educação no Estado de Minas Gerais, já que suas unidades se estendem pelas cidades de Belo Horizonte, Contagem, Betim, Ouro Branco e Uberlândia. A instituição atende do berçário ao ensino médio; uma de suas unidades oferta cursos em nível superior e possui também uma outra de idiomas, além das suas unidades sociais que ministram gratuitamente educação a crianças e adultos na capital e no interior do Estado. O caráter confessional da instituição marca a sua história desde o início, quando cuidava da educação de filhos de missionários religiosos. O voluntariado realizado pelos seus membros fundadores promoveu a conquista do título de Filantropia, possibilitando a extensão de sua atuação ao âmbito social. Assim sendo, a instituição guarda algumas características consideradas diferenciais para o estudo dos valores dos que ali trabalham. 
Conforme Porto e Tamayo (2008), diversos autores são categóricos em afirmar que os valores orientam e guiam a vida das pessoas, daí a importância de pesquisá-los.

Para o desenvolvimento do tema, torna-se fundamental a compreensão do conceito na literatura de valores, o qual conta com dimensões, como: sistema de valores, tipos motivacionais e prioridades axiológicas (Porto \& Tamayo, 2008). Vislumbra-se a importância desta pesquisa já que os valores influenciam as mudanças da sociedade, o comportamento das pessoas, o julgamento de ações, além de permitir diferenciar nações, grupos e organizações (Porto \& Tamayo, 2008).

A opção do estudo sobre valores com o sujeito "professor" deve-se ao fato de esse profissional estar na base da responsabilidade pela formação e desenvolvimento de uma sociedade (Tardif, 2002) apesar de progressivamente pouco valorizado. Além disso, a docência é vista como uma profissão que envolve sofrimento, desgaste físico e mental, advindos das exigências permanentes da profissão, as quais impactam o bem-estar e a saúde para a maioria dos profissionais da categoria (Dejours, 1988).

O foco sobre professores é especialmente relevante, pois eles ocupam uma posição fundamental em relação aos demais agentes sociais, tendo em vista o trabalho cotidiano realizado junto aos seus alunos, tornando-se os principais agentes e intermediadores da cultura e dos saberes escolares (Tardif, 2002).

A perspectiva de abordagem desse tema a partir da referida profissão considera esses atores como sujeitos profissionais que possuem, utilizam e produzem saberes específicos e justamente essa capacidade favorece um rico debate, sendo agregadora para a sociedade quando os temas valores do trabalho e valores organizacionais são trazidos à luz pelo prisma dos professores (Tardif, 2002).

Segundo Tardif (2002), a prática educativa assemelha-se a uma arte, ao buscar atingir objetivos exteriores a ela mesma. Essa profissão também estabelece uma técnica guiada por valores que se consolidam pelo envolvimento de todos os agentes, sendo o ser humano agente de suas transformações e com comportamento que reflete aceitação, ou não, em termos de aderência voluntária a normas sociais. Além disso, o ambiente onde ele trabalha, a escola, exala interação, devido ao caráter essencialmente social do ato de educar. Conduzir esta pesquisa com professores leva em conta as possibilidades de obter nortes para o tema valores organizacionais e do trabalho, dadas as especificidades dessa categoria profissional.

Tendo em vista a relevância dos sujeitos de pesquisa, os professores, para a formação da sociedade, este estudo poderá fomentar o debate sobre valores laborais e organizacionais a despeito da percepção acolhida desses valores no âmbito individual, pois a influência dos valores é sentida nas motivações pessoais e organizacionais, na condução dos processos e na determinação de escolhas, ou seja, nas ações dos indivíduos (Tamayo, 2008).

Tratar o tema valores do trabalho e valores organizacionais, à luz das perspectivas de professores, especificamente, de uma escola filantrópica confessional assume um contorno especial dada a relevância social desse tipo de instituição. O fato de ser filantrópica implica objetivos prioritários divergentes da distribuição dos lucros e, por ser confessional, seria de esperar valores do trabalho e organizacionais condizentes com a vertente religiosa à qual pertence, os quais devem ser percebidos pelos professores que compõem seu quadro de empregados, uma vez que podem assumir, ou não, um papel estritamente profissional na condução de suas atividades laborais, aceitando ou rejeitando os princípios religiosos adotados pela organização.

Note-se, também, que, quando investigados os temas específicos de valores organizacionais e valores do trabalho, os resultados ganham um contorno de ferramenta de gestão, em face da forte influência que os rumos organizacionais têm com a perspectiva dos empregados e a dedicação dispensada por estes aos interesses organizacionais (Porto \& Tamayo, 2008). Assim sendo, os resultados desta pesquisa podem contribuir, secundariamente, para melhorias nos processos de gestão, principalmente no que tange às políticas e práticas de gestão de pessoas efetuadas pela organização, podendo somar na formulação de metas e recompensas no trabalho.

Este artigo está dividido em cinco partes, sendo a primeira, esta introdução, a segunda, o referencial teórico que abraça os temas centrais (valores, valores organizacionais e valores no trabalho), a terceira, a metodologia, delineada para a pesquisa empírica, a quarta, a apresentação e análise dos dados e a quinta, as considerações finais. Seguem, ao final, as referências das obras citadas ao longo do estudo e os apêndices. 
Valores organizacionais e do trabalho: um estudo com professores de uma escola filantrópica e confessional de Belo Horizonte (MG)

\section{Referencial Teórico}

O referencial teórico deste estudo está dividido em três partes, quais sejam: valores, valores organizacionais e valores do trabalho.

\subsection{Conceitos de Valores}

O tema valores permeia várias perspectivas: psicológica, sociológica e antropológica, como afirmam Ros e Gouveia (2006). Na Filosofia, os valores constituem a fonte de reflexão do que é bom ou do que é belo. Na Antropologia, os valores são fundamentais na compreensão da cultura. Na Sociologia, são temas recorrentes de estudo, já que fundamentam a sociedade e justificam as ações dos indivíduos. Nas abordagens evolucionistas, a transmissão dos valores é um fenômeno importante para a compreensão da sobrevivência da espécie humana (Porto \& Tamayo, 2008).

Os valores, segundo Schwartz (2005a), podem ser entendidos como um esquema de julgamentos que leva em conta as preferências do que é mais desejável para o indivíduo. Servem como tipos motivacionais diretamente ligados às necessidades mais básicas do ser humano e podem ser entendidos como preditores de comportamentos.

Valores também são conceituados como crenças que expressam a linguagem e representam necessidades biológicas e sociais, dada a necessidade de sobrevivência do tecido social. As crenças que constituem os valores do indivíduo são provenientes da interação do sujeito com o meio social em que está inserido,fortemente balizados pelos contextos social, político, cultural e econômico (Santos, Fischer, Milfont, \& Gouveia, 2008).

Ros e Gouveia (2006) traçam uma perspectiva histórica da conceituação de valores, na qual eles são concebidos em relação às atividades. Parsons, um dos clássicos citados pelos autores, destaca valor como a concepção influenciadora, seja individual ou coletiva, que exerce influência direta nas escolhas. Ros e Gouveia (2006) ainda destacam Rokeach como um dos precursores na psicologia a tratar do tema, para quem valores são como crenças transituacionais, a saber: terminais, ou seja, correlacionados à existência humana; e sociais, isto é, os de caráter interpessoal.

Porto (2005) enumera as categorias de valores, passando dos valores morais aos financeiros, valores de pessoas e de grupos. Segundo o autor, os pesquisadores dão real importância à esfera dos valores humanos, com ênfase sobre as categorias de valores pessoais, laborais, organizacionais e culturais.

As relações entre valores, atitudes e comportamentos são estabelecidas desde construtos primários: valores dão significado afetivo e exercem influência nas avaliações de situações e escolhas referentes a tais avaliações. Por outro lado, eles sofrem influência de concepções ideológicas e também da cultura ou meio em que os indivíduos estão inseridos (Porto, 2005).

As prioridades atribuídas aos valores podem expressar aquilo que é bom e importante para os indivíduos, para a sociedade e para as organizações que estes compõem, o que irá influenciar as atitudes e decisões comportamentais (Tamayo, 2005).

Porto e Tamayo (2008) também destacam as contribuições de Schwartz como a principal teoria sobre valores na atualidade. Schwartz define valores como metas desejáveis, transituacionais que variam em sua importância e servem como princípios para as pessoas (Ros \& Gouveia, 2006). Schwartz afirma:

1) Valores são crenças intrinsecamente ligadas à emoção e não a ideias objetivas e frias;

2) Valores são um construto motivacional, que se refere a objetivos desejáveis que as pessoas se esforçam para obter;

3) Valores transcendem situações e ações específicas, sendo objetivos abstratos;

4) Valores guiam a seleção e avaliação de ações, políticas, pessoas e eventos, atuando como padrões e critérios;

5) Valores são ordenados pela importância relativa aos demais, os valores das pessoas formam um sistema ordenado de prioridades axiológicas que as caracterizam. 
Para Porto e Tamayo (2008), a distinção entre os valores se dá pelo tipo de objetivo ou motivação que o valor expressa. Nesse sentido, eles apresentam uma teoria que formula dez tipos motivacionais, os quais estão detalhados na Figura 1.

\begin{tabular}{|c|l|}
\hline $\begin{array}{c}\text { Tipo } \\
\text { motivacional }\end{array}$ & \multicolumn{1}{c|}{ Definição } \\
\hline Poder & $\begin{array}{l}\text { Status social das pessoas e recursos (no que tange à busca e à preservação da posição } \\
\text { social inserida em um sistema social) }\end{array}$ \\
\hline Realização & Sucesso pessoal mediante a demonstração de competência segundo critérios sociais. \\
\hline Hedonismo & Prazer e senso de gratificação para consigo. \\
\hline Estimulação & Entusiasmo, novidade e desafio na vida. \\
\hline Autodireção & Pensamento independente e escolha da ação, criatividade e exploração. \\
\hline Universalismo & $\begin{array}{l}\text { Compreensão, apreciação, tolerância e proteção do bem-estar de todas as pessoas e da } \\
\text { Natureza. }\end{array}$ \\
\hline Benevolência & $\begin{array}{l}\text { Preservação e intensificação do bem das pessoas com quem se mantém contatos pessoais } \\
\text { frequentes. }\end{array}$ \\
\hline Tradição & $\begin{array}{l}\text { Respeito aos costumes e ideias providos pela cultura tradicional e pela religião, } \\
\text { comprometimento com eles e sua aceitação. }\end{array}$ \\
\hline Conformidade & $\begin{array}{l}\text { Restriçães das açães, inclinaçães e impulsos que podem perturbar e ferir os outros ou } \\
\text { violar as expectativas e normas sociais. }\end{array}$ \\
\hline Segurança & \begin{tabular}{l} 
Segurança, harmonia e estabilidade, da sociedade, dos relacionamentos e de si mesmo. \\
\hline
\end{tabular} \\
\hline
\end{tabular}

Figura 1 - Tipos motivacionais de Schwartz.

Fonte: Teixeira (2008, p. 207).

Os valores podem conflitar ou serem coincidentes entre si. Ações que expressam valores têm consequências práticas, fisiológicas e sociais (Porto \& Tamayo, 2008). A Figura 2 retrata essa congruência e conflito entre os tipos motivacionais, considerando quatro polos: Autotranscendência x Autopromoçao; e Abertura à mudança x Conservação.

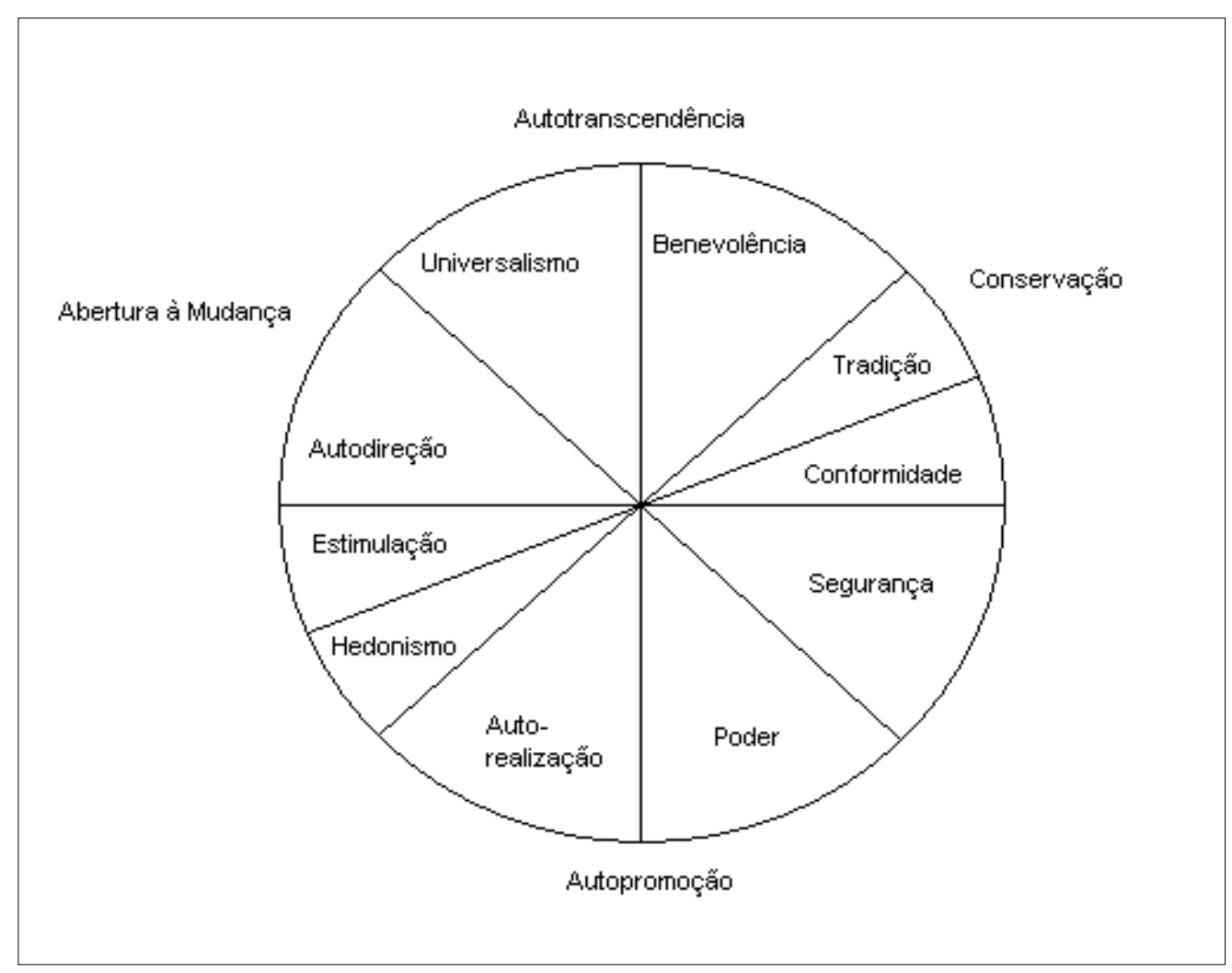

Figura 2 - Modelo teórico das relações entre os tipos Motivacionais, tipos de valores de ordem superior e dimensões de valores bipolares

Fonte: Schwartz (2005a, p. 30).

Porto e Tamayo (2008) salientam que, em um nível mais básico, os valores formam um continuum de motivações relacionadas ao apresentado na figura anterior. 
Valores organizacionais e do trabalho: um estudo com professores de uma escola filantrópica e confessional de Belo Horizonte (MG)

Cabem, ainda, considerações sobre a teoria funcionalista dos valores humanos (Santos, Fischer, Milfont, \& Gouveia, 2008). Essa teoria admite quatro suposições teóricas principais vinculadas à compreensão dos valores:

a) Natureza humana, que assume a natureza benevolente ou positiva dos seres humanos;

b) Princípios-guias individuais, em que a cultura incorpora os valores para a sobrevivência do grupo, tornando-os desejáveis;

c) Base Motivacional, em que valores são demandas além das motivações cognitivas das necessidades institucionais e societais;

d) Caráter Terminal, que abrange duas funções consensuais dos valores: guiam ações humanas e expressam suas necessidades.

Uma classificação proposta por Santos, Fischer, Milfont e Gouveia (2008) refere-se à possibilidade de valores serem materialistas ou humanitários. Enquanto o primeiro conjunto relaciona-se com a vida prática, o segundo expressa uma orientação universal, baseada em ideias e princípios mais abstratos.

Segundo Porto e Tamayo (2008), o comprometimento organizacional se estabelece a partir da compatibilidade entre valores pessoais e organizacionais. Essa afirmação tem um papel orientador, expressando que valores são critérios e metas transituacionais ordenados por sua importância como princípios que guiam a vida, quer na esfera do trabalho que realiza, quer na da organização onde tal trabalho se concretiza. É importante frisar que comprometimento organizacional não é tema deste estudo, mas a literatura informa a sua importância para a consecução dos fins organizacionais (Fleury, 1991; Bastos \& Borges-Andrade, 1995), o que remete, mais uma vez, para o caráter significativo do estudo dos valores, no escopo laboral.

\subsection{Valores Organizacionais}

Os valores organizacionais orientam a vida das organizações; eles compõem a estrutura da cultura organizacional. Os membros das organizações tendem a assimilar com facilidade esses valores e aplicá-los, servindo como uma linha mestra a seguir; assim, os valores possibilitam a integração organizacional (Ros \& Gouveia, 2006).

Ainda que a identificação com a estrutura física seja um sinal evidente para denotar um relacionamento entre um indivíduo e uma organização, dando a esta uma condição de existência quase humana, consideram-se também os equipamentos e tecnologias para diferenciar determinada organização e as pessoas que compõem seus quadros. Embora os aspectos identificação e diferenciação sejam extremamente relevantes, contudo, não constituem a estrutura fundamental. 0 elemento fundamental é a interação entre organização e seus membros, as atividades por eles executadas e o próprio funcionamento da organização (Ros \& Gouveia, 2006).

Valores organizacionais se diferenciam de valores pessoais dos membros de uma organização. A organização tem um conjunto de valores próprios, passíveis de divergência com os valores individuais dos seus componentes. Os valores pessoais são previamente adquiridos na formação do caráter e na história de vida de cada indivíduo. Ao passar a constituir a organização, o indivíduo vivenciará contrastes entre seus valores pessoais, transmitidos pelo meio no qual está inserido, e os valores estabelecidos frente às demandas específicas de um negócio pela alta gestão organizacional (Ros \& Gouveia, 2006).

Valores organizacionais podem ter sua origem na convicção de um indivíduo de destaque da organização, como o fundador ou o executivo responsável por ela. Assim, valores organizacionais podem representar soluções para problemas próprios da organização, evoluindo para uma percepção coletiva como fator norteador (Ros \& Gouveia, 2006).

Na perspectiva de Tamayo (Ros \& Gouveia, 2006), valores organizacionais podem ser definidos como princípios ou crenças, organizados hierarquicamente, relativos a comportamentos ou metas organizacionais desejáveis que orientam a vida da organização e estão a serviço de interesses individuais, coletivos e mistos. Tamayo e Gondim (1996) distinguem três aspectos básicos nos valores organizacionais:

a) Cognitivo - são crenças que expressam a filosofia fundamental da organização sobre o que é ou não desejável para ela; os valores constituem parâmetros para julgar e justificar o comportamento individual e organizacional; 
b) Motivacional - expressa o interesse e as metas da organização, determinando a quantidade de esforço dos membros em aderir a determinados comportamentos esperados pela organização e influenciando a imagem e autoestima da organização;

c) Hierárquico - os valores das organizações expressam preferências por determinados comportamentos, metas ou estratégias. Portanto, é da natureza dos valores se organizar de acordo com a importância dessas preferências (Ros \& Gouveia, 2006).

Os valores organizacionais apoiam as atitudes, motivam a construção das metas e objetivos, determinam as formas de julgar a conduta e os acontecimentos organizacionais e orientam a vida da organização (Ros \& Gouveia, 2006).

Baseando-se no conceito de consciência social de Durkheim, pode-se afirmar que a realidade organizacional é constituída pelo pensamento coletivo, ou seja, pelos modelos mentais compartilhados pelos membros da organização (Ros \& Gouveia, 2006).

De acordo com a abordagem dos valores culturais propostos por Ros, Schwartz e Surkiss (1999), pode-se afirmar que toda organização enfrenta três exigências fundamentais:

a) a inevitável relação entre o indivíduo e o grupo, que implica a tentativa de compartilhar os interesses individuais e coletivos;

b) a necessidade de estabelecer uma estrutura que garanta a obtenção das metas e objetivos da organização e

c) a relação da organização com o meio ambiente físico e social.

Outro aspecto relevante nos valores organizacionais é a descrição de cargos, estabelecendo não só o papel que cada participante da organização irá desempenhar, como também o cargo que irá ocupar, estabelecendo, assim, as normas que dão o norte aos membros das organizações (Tamayo, 2008).

Os valores alinham as prioridades para indivíduos e as organizações, exercendo impacto e determinando mudanças, assim sendo, os valores exercem influências positivas e negativas no ambiente organizacional conforme resultados que ensejam. Desse modo, os valores exercem grandes influências no ambiente organizacional "podendo influenciar, de forma mais elaborada, tanto os comportamentos pró-sociais quanto a percepção das ações negativas vivenciadas no sistema organizacional" (Tamayo, 2005).

Note-se que os valores organizacionais são forjados por pessoas, portanto, sofrem influência dos valores pessoais dos mesmos, passando por uma gama pessoal de conceitos acerca do que seja bom para si, para os outros e para a sociedade. Essa relação entrelaçada de valor pessoal e organizacional aproxima a estrutura desses dois conceitos, fazendo com que a motivação de sustentação de ambos seja a mesma (Tamayo, 2005).

Dessa forma, Tamayo (2005) considera que a estrutura motivacional é a mesma para a organização e para as pessoas. A importância das organizações se faz por se constituírem em um lugar privilegiado onde se forma a identidade profissional do trabalhador e que o conduz à realização pessoal, social e profissional. É no ambiente organizacional que o indivíduo atinge grande parte de sua felicidade. Assim, as metas organizacionais integram inevitavelmente as metas e motivações pessoais (Tamayo, 2005).

Assim como pessoas, as organizações possuem suas necessidades, que devem ser satisfeitas. Nesse sentido, Tamayo (2005) considera que os valores organizacionais podem ser representações cognitivas dessas necessidades (Tamayo, 2005). Nessa perspectiva, valores constituem-se em instrumentos que permitem gerar entendimento sobre a cultura organizacional. Valores organizacionais têm funções importantes, atuando como mediadores nos conflitos, contribuindo para a solução dos problemas das organizações e promovendo a sobrevivência das mesmas (Teixeira, 2008).

\subsubsection{Modelos teóricos de valores organizacionais}

Tamayo (2008) apresenta, a priori, dois modelos para representar a estrutura dos valores organizacionais, sendo eles: o modelo cultural e o modelo das motivações pessoais. O modelo cultural baseia-se no fato de que toda organização é e possui uma cultura. Assim como os indivíduos, as organizações têm necessidades que precisam ser satisfeitas, a fim de garantir sua continuidade. Sendo assim, elas têm três problemas fundamentais: 
Valores organizacionais e do trabalho: um estudo com professores de uma escola filantrópica e confessional de Belo Horizonte (MG)

a) balancear a relação entre o individual e o coletivo, visando ao equilíbrio entre ambos;

b) desenvolver uma estrutura que garanta a obtenção das metas e dos objetivos da organização;

c) manter uma relação com o meio ambiente físico e social (Tamayo, 2008).

Esse modelo afirma que os valores organizacionais estão organizados em três dimensões bipolares que representam as alternativas de respostas a essas demandas: autonomia versus conservadorismo, hierarquia versus igualitarismo e harmonia versus domínio (Ros \& Gouveia, 2006).

A dimensão autonomia versus conservadorismo representa a busca para compatibilizar os interesses do indivíduo e os da organização. A característica fundamental desse polo é a busca e a promoção de mudanças, inovações e transformações organizacionais (Ros \& Gouveia, 2006). As organizações que favorecem a autonomia estimulam a criatividade, liberdade e inovação. Já o lado conservador estimula a manutenção do status quo.

A dimensão hierarquia versus igualitarismo expõe suas componentes como alternativas para a criação de um sistema organizacional que defina as funções que devem ser executadas, a relação entre a organização e suas unidades e também com seus membros. Valores como autoridade, fiscalização, supervisão e influência operam preferencialmente nessa dimensão. A opção por uma estrutura igualitária é oposta a essa; nesse outro polo, destacam-se valores, como: justiça, equidade e responsabilidade.

A terceira dimensão fala da relação com o meio ambiente físico e social. Toda organização deve optar por um tipo de relação com o meio ambiente. Um dos polos (a harmonia) caracteriza-se pela relação harmoniosa com a natureza e as demais organizações. Na outra ponta dessa dimensão, está o domínio, ou seja, uma interação desequilibrada com o consumo da natureza, o domínio de mercado e de tecnologias, sem preocupação com as consequências de suas ações sobre terceiros.

O segundo modelo destacado por Tamayo (2008) é o modelo de Motivações Pessoais, que afirma a existência de "isomorfismo motivacional" entre valores pessoais e organizacionais. Nele, os valores espelham motivações semelhantes do indivíduo e do grupo, do trabalhador e da organização, refletindo a congruência entre as metas do empregado e as da organização. O modelo de motivação pessoal baseia-se na compreensão de que os valores organizacionais estruturam os valores pessoais, com foco no coletivo e não no individual. Schwartz, referência fundamental para os estudos do tema em questão, relaciona dez motivações básicas para os indivíduos, sendo elas: autodeterminação, estimulação, hedonismo, realização, poder, segurança, conformidade, tradição, benevolência e universalismo. Por essa teoria, postula-se que um valor organizacional seja a soma de dois os mais tipos motivacionais (Tamayo, 2008).

\subsubsection{Modelos e escalas de valores organizacionais}

Consideram-se três instrumentos de medida de valores organizacionais no Brasil. Os modelos apresentam distinções entre si, como observado adiante.

\subsubsection{Escala de Valores Organizacionais - EVO}

Essa escala foi constituída e validada por Tamayo e Gondim (1996). Sua construção baseia-se na forma empírica, ou seja, ela não se vale de um modelo para representar a estrutura dos valores organizacionais. Os autores se apoiaram em uma amostra de 113 funcionários de cinco organizações, públicas e privadas. O questionário solicitou que os respondentes relacionassem cinco valores de suas respectivas organizações, com uma breve citação acerca de suas indicações. Os autores identificaram mais de 500 valores que, em posterior análise, foram reduzidos para 48. Para validação, os autores utilizaram uma amostra composta por 574 indivíduos de 16 empresas, públicas e privadas, de ambos os sexos e com idade média de 58 anos. Dez itens foram eliminados por não atenderem aos critérios estabelecidos para as cargas fatoriais. Os 38 restantes foram distribuídos em cinco fatores: eficácia/eficiência, interação no trabalho, gestão, inovação e respeito ao emprego.

O fator eficácia/eficiência é composto por nove valores: eficácia, eficiência, qualidade, produtividade, comprometimento, planejamento, pontualidade, competência e dedicação. Esse fator mede a importância dada pela empresa, na percepção dos sujeitos, aos fatores de eficácia e eficiência apresentados na produção e qualidade de seus produtos e serviços. 
Já o fator interação no trabalho é composto por 10 itens que dizem respeito à interação no trabalho: um alto índice nesse fator representa que os funcionários veem como positiva a organização que valoriza a interação no trabalho. Os valores nesse item são: abertura, coleguismo, amizade, cooperação, sociabilidade e flexibilidade.

Gestão, por sua vez, refere-se a políticas organizacionais, tradicionais e hierárquicas, traduzidas da seguinte forma: tradição, hierarquia, obediência, fiscalização, supervisão, postura profissional e organização.

O quarto fator, inovação, é constituído de quatro valores: pesquisa, integração interinstitucional, modernização dos recursos materiais e probidade. Esse fator, quando muito estimado, indica aos funcionários a preocupação da organização com a inovação.

Por último, o fator respeito ao empregado é constituído de oito valores, quais sejam: respeito, reconhecimento do mérito, qualificação dos recursos humanos, polidez, honestidade, plano de carreira, harmonia e justiça. Nesses valores, a tônica é a valorização do colaborador, uma preocupação com os empregados gera um alto índice nesse fator.

\subsubsection{Inventário de valores organizacionais - IVO}

Esse inventário foi construído por Tamayo, Mendes e Paz (2000). Os autores fundamentaram o trabalho no modelo dos valores culturais que apresenta três dimensões bipolares, a saber: autonomia versus conservadorismo, hierarquia versus igualitarismo, e harmonia versus domínio. Eles se valeram do modelo do EVO nesse novo instrumento, pois consideraram que nele se expressam adequadamente alguns dos construtos axiológicos que se pretendia medir. Novos itens foram constituídos para representar tipos motivacionais não contemplados no EVO, focando prioritariamente os polos de igualitarismo e autonomia, menos representados no levantamento de Tamayo e Gondim (1996). Todos os itens foram apresentados a três grupos de 6 a 8 empregados, para verificar a clareza do questionário, no seu aspecto semântico. Por fim, o inventário ficou composto de 37 itens, avaliados pelo respondente por meio de uma escala de 7 pontos (0 a 6) (Tamayo, 2008). O inventário conduz a seis polos, a saber:

a) Autonomia - tendência de a empresa considerar o empregado como entidade autônoma, capaz de perseguir seus interesses e determinar suas metas em congruência às metas e normas organizacionais;

b) Conservadorismo - mede o quanto a organização acredita ser importante a manutenção dos usos, costumes e estrutura de poder já existentes, promovendo a manutenção do status quo e a limitação de ações que possam interferir nesse estado;

c) Hierarquia - avalia a valorização por parte da organização de: autoridade, poder social, supervisão, legitimação hierárquica de recursos e papéis sociais;

d) Igualitarismo - detém-se na preocupação com o bem-estar dos outros e da organização em geral, e na adaptação de uma gestão mais participativa e equitativa;

e) Harmonia - reflete relações saudáveis, harmônicas e igualitárias com o meio ambiente;

f) Domínio - diz respeito à vontade assertiva da empresa por meio do domínio dos recursos materiais, do mercado, da tecnologia e do conhecimento específico na área de atuação (Tamayo, 2008).

\subsubsection{Inventário de perfis de valores organizacionais - IPVO}

O IPVO apresenta 48 itens distribuídos em oito fatores. Foi construído e validado por Oliveira e Tamayo (2004). Inicialmente, os autores elaboraram definições constitutivas e operacionais para cada um dos tipos motivacionais de valores organizacionais esperados, tendo como base a teoria de valores humanos (Schwartz, 2005a, b). Os itens foram elaborados a partir de uma ideia de empresa hipotética em que cada perfil dá ênfase a um valor organizacional. Os entrevistados foram levados a considerar a equivalência dessa organização hipotética com a organização em que os mesmos exercem suas funções. Foram elaborados perfis e, para cada um deles, o indivíduo deveria responder à pergunta: quanto essa organização aqui descrita se parece com aquela na qual você trabalha? Respostas possíveis são: "muito parecida com minha organização", "parecida", "mais ou menos parecida", "Não se parece com a minha organização", "Não se parece nada com a minha organização". Portanto, o IPVO não apresenta uma escala de resposta numérica. Porém, o 
pesquisador atribuiu a cada resposta na sequência um valor de 5 a 0 , visando ao tratamento estatístico (Tamayo, 2008). A validação do IPVO se deu com amostra de 853 empregados de empresas públicas e privadas (Tamayo, 2008).

Oliveira e Tamayo (2004) apresentam oito fatores ou tipos motivacionais que representam princípios ou guias da vida organizacional, sendo tais fatores os seguintes: autonomia, bem-estar, realização, domínio, prestígio, conformidade, tradição, preocupação com coletividade. Observem-se seus conceitos:

a) Autonomia - a organização persegue a melhoria dos seus funcionários, produtos e serviços, gerando e estimulando novos desafios, curiosidades, experiências e definição de objetivos profissionais;

b) Bem-estar - retrata a preocupação da organização em propiciar satisfação ao trabalhador, atentando para a qualidade de vida no trabalho;

c) Realização - avalia o sucesso, baseado em uma demonstração de competência, da organização e de seus colaboradores;

d) Domínio - lista itens relativos ao poder, cuja meta central é a obtenção de status, lucro, controle sobre pessoas e recursos e a busca de uma posição dominante no mercado;

e) Prestígio - avalia a busca por parte da organização por prestígio, admiração e respeito da sociedade por causa da qualidade dos seus produtos e serviços;

f) Conformidade - demonstra o grau de respeito dado pela organização às regras e modelos de comportamento, tanto no ambiente de trabalho, quanto na relação com outras organizações;

g) Tradição - considera a dedicação da organização para preservar o respeito aos usos e costumes e práticas organizacionais;

h) Preocupação com a coletividade - destaca a preocupação com igualdade, justiça, lealdade, honestidade e sinceridade nas práticas organizacionais e no relacionamento com todos (Tamayo, 2008).

Tendo em vista a amplitude dessa última escala, ela foi adotada para fins do estudo desenvolvido neste estudo.

\subsection{Valores do Trabalho}

O estudo dos valores do trabalho objetiva compreender os elementos motivacionais que influenciam diversos aspectos relacionados ao trabalho, entre os quais se destacam comprometimento organizacional, bem-estar, estresse e resultados do trabalho (Campos, 2008).

“Valores do trabalho consistem em princípios ou crenças a respeito de metas ou recompensas desejáveis, hierarquicamente organizados, conseguidos por meio do trabalho" (Campos, 2008, pp. 389-390). Eles são referências avaliativas sobre os resultados e o contexto do trabalho, de modo semelhante ao comportamento organizacional e às escolhas de alternativas no âmbito do trabalho (Campos, 2008).

Os valores relativos ao trabalho fundamentam-se em características cognitivas, formando um conjunto de crenças acerca do que é desejável ou não no trabalho, e hierárquicas, uma vez que as pessoas avaliam de acordo com a importância atribuída a cada uma delas "ao longo de um contínuo de importância" (Porto \& Tamayo, 2003).

Porto (2005) classifica em três níveis os Valores do Trabalho, a saber: pessoais, relativos a princípios que guiam a vida dos indivíduos no trabalho; sociais, relacionados aos princípios percebidos por outras pessoas; e, por fim, os culturais, que têm forte carga de confirmação do grupo e são compartilhados por seus membros, pela liderança ou pessoas tidas como importantes, como aquelas da alta hierarquia dentro da organização (Teixeira, 2008). Já para Hofstede, os valores do trabalho são classificados em individuais, coletivos e universais. Contudo, diversos autores, entre eles Rokeach, consideram que valores no trabalho têm sua "durabilidade" passível de mudanças (Teixeira, 2008).

Diversos autores têm apresentado suas definições de valores do trabalho, como as relacionadas na Figura 3. 


\begin{tabular}{|l|l|}
\hline \multicolumn{1}{|c|}{ Autor } & \multicolumn{1}{c|}{ Definição } \\
\hline $\begin{array}{l}\text { Samuel \& Lewin- } \\
\text { Epstein (1979) }\end{array}$ & $\begin{array}{l}\text { Valores laborais são aqueles que determinam os modos, meios, comportamentos ou } \\
\text { os resultados que são preferíveis sobre outros. }\end{array}$ \\
\hline Nord et al. (1986) & $\begin{array}{l}\text { Valores laborais são estados de existência desejados pelas pessoas e que são } \\
\text { sentidos como possíveis de realização por meio do trabalho. }\end{array}$ \\
\hline Hofstede (1997) & Valores são uma tendência geral para preferir certo estado de coisas do trabalho. \\
\hline Dose (1997) & $\begin{array}{l}\text { Valores do trabalho são padrões avaliativos relativos ao trabalho e ao contexto de } \\
\text { trabalho por meio dos quais o indivíduo discerne o que é “certo" ou acessa a } \\
\text { importância das preferências. }\end{array}$ \\
\hline $\begin{array}{l}\text { Sagie \& Elizur } \\
\text { (1996) }\end{array}$ & $\begin{array}{l}\text { Valores laborais definem-se como a importância dada pelos indivíduos a certos } \\
\text { resultados obtidos no contexto do trabalho. }\end{array}$ \\
\hline Schwartz (1999) & $\begin{array}{l}\text { Valores laborais referem-se a metas ou recompensas que as pessoas buscam por } \\
\text { meio do trabalho. }\end{array}$ \\
\hline $\begin{array}{l}\text { Ros, Schwartz e } \\
\text { Surkiss (1999) }\end{array}$ & $\begin{array}{l}\text { Valores laborais são princípios ou crenças sobre comportamentos ou metas } \\
\text { desejáveis, hierarquicamente organizados, que guiam as avaliações sobre os } \\
\text { resultados e contexto do trabalho, bem como a escolha de alternativas de trabalho. }\end{array}$ \\
\hline $\begin{array}{l}\text { Porto \& Tamayo } \\
\text { (2003) }\end{array}$ & $\begin{array}{l}\text { Valores laborais são princípios ou crenças sobre comportamentos ou metas } \\
\text { desejáveis, hierarquicamente organizados, que as pessoas buscam por meio do } \\
\text { trabalho e que guiam as suas avaliações sobre os resultados e contexto do } \\
\text { trabalho, bem como o seu comportamento e a escolha de alternativas de trabalho. }\end{array}$ \\
\hline
\end{tabular}

Figura 3 - Definições de Valores do Trabalho

Fonte: Teixeira (2008, p. 181).

Conhecer essas questões relativas aos valores do trabalho possibilita aos gestores melhores condições para fazer fluir as organizações, colaborando com a proposição de metas que estimulem os indivíduos e as organizações a se desenvolverem (Porto \& Tamayo, 2008).

Note-se, ainda, que o trabalho tem sua importância destacada na literatura acerca de valores, sendo considerado como uma das mais importantes esferas da vida humana. Dedicar-se ao estudo dos valores do trabalho faz emergir questões relevantes que exercem influências diretas sobre o ser humano (Teixeira, 2008). Para entender como isso se processa nos indivíduos, pode-se utilizar os modelos analíticos descritos a seguir.

\subsubsection{Modelos analíticos sobre Valores do Trabalho}

Dentre os modelos analíticos desenvolvidos para o estudo dos valores no trabalho, Porto e Tamayo (2008) destacam dois, o de Super e o de Elizur.

Super (1957) apresenta uma síntese das motivações que conduzem um indivíduo a gostar ou não do seu trabalho. Ele enumera as três principais necessidades que podem ser satisfeitas através do trabalho. Essas necessidades são compostas por fatores específicos que as distinguem (Porto \& Tamayo, 2008).

a) necessidades de relações humanas - os indivíduos almejam serem reconhecidos como pessoas. Surgem então os fatores de independência e tratamento justo. É a relação entre pessoas que as distingue, possibilitando diferenciações em termos de status;

b) necessidade de trabalho - considera a atividade do trabalho, diante do conteúdo do próprio trabalho, e o contexto do trabalho, considerando o ambiente em que o trabalho é desenvolvido e as pessoas com quem é desenvolvido. Dá-se ao empregado a oportunidade de autoexpressão e variedade do trabalho;

c) necessidade de sustento - essa necessidade está na base da pirâmide; não satisfeita comprometerá as demais. Se atendida essa necessidade, as demais ganham o mesmo status de importância, na ótica do indivíduo. Essa necessidade envolve o ganho recebido no que tange ao valor bruto e ao relativo, além da segurança no trabalho.

Super (1957) tem especial destaque na literatura dos valores do trabalho por sua contribuição ao tema desenvolvimento vocacional. Entretanto, o modelo apresentado por ele confunde os valores no trabalho e a satisfação no trabalho, conforme demonstrados por Porto e Tamayo (2008) e outros estudiosos (Porto \& Tamayo, 2008).

Já Elizur (1984) propôs um modelo baseado em duas facetas que constituem o espaço conceitual dos valores laborais. Duas facetas são consideradas pelo autor: a faceta A, identificada como Modalidade de Resultado, composta de três elementos: Instrumental, Afetivo e Cognitivo; já a faceta B mantém relação com o desempenho de tarefa. Posteriormente, Elizur e Sagie (1999) 
passam a denominar a faceta B de Foco e seus elementos de Difusos e Focados. Essa segunda faceta abrange dois fatores: Recurso ou difuso; e Recompensa ou Focado. Na Figura 4, pode-se visualizar os elementos e definições de tais facetas:

\begin{tabular}{|c|c|c|}
\hline Faceta & Elementos & Definição \\
\hline \multirow{3}{*}{$\begin{array}{l}\text { A - Modalidade } \\
\text { do resultado }\end{array}$} & Instrumental & $\begin{array}{l}\text { Referem-se aos resultados do trabalho de natureza } \\
\text { material, como pagamento, benefícios, condições de } \\
\text { trabalho. }\end{array}$ \\
\hline & Afetivo & $\begin{array}{l}\text { Referem-se a relacionamentos sociais, como } \\
\text { relacionamentos com colegas e chefia. }\end{array}$ \\
\hline & Cognitivo & $\begin{array}{l}\text { Referem-se a recompensas psicológicas do trabalho como } \\
\text { interesse, responsabilidade e independência. }\end{array}$ \\
\hline \multirow{2}{*}{$\begin{array}{l}\text { B - Relação com } \\
\text { o desempenho da } \\
\text { tarefa ou foco }\end{array}$} & $\begin{array}{l}\text { Recurso ou } \\
\text { difuso }\end{array}$ & $\begin{array}{l}\text { Referem-se a recompensas oferecidas antes do } \\
\text { desempenho da tarefa ou não condicionadas ao seu } \\
\text { trabalho, como plano de benefícios e condições de } \\
\text { trabalho. }\end{array}$ \\
\hline & $\begin{array}{l}\text { Recompensa ou } \\
\text { focado }\end{array}$ & $\begin{array}{l}\text { Referem-se a resultados oferecidos após o desempenho } \\
\text { da tarefa ou em troca do resultado, como } \\
\text { reconhecimento, status, progressão na carreira. }\end{array}$ \\
\hline
\end{tabular}

Figura 4 - Facetas dos valores laborais e seus elementos

Fonte: Porto \& Tamayo (2008, p. 299).

Contudo Ros, Schwartz e Surkiss (1999), ao examinarem as análises de Elizur (1984), apontam para um quarto fator denominado prestígio, que corrigiria vários problemas na análise de Elizur. Esse fator, inicialmente denominado cognitivo por Elizur, é dividido em duas dimensões: intrínseca e prestígio.

Ros, Schwartz e Surkiss (1999) revisaram a literatura acerca de valores laborais. Ao perceberem a lacuna existente nas pesquisas da área de valores, eles apresentaram uma alternativa baseada na teoria de valores de Schwartz $(2005 a, b)$, a qual identificou uma estrutura universal para os valores humanos (Porto \& Tamayo, 2008), já descrita anteriormente. Ao analisarem a literatura sobre valores do trabalho, os autores constataram a falta do tipo motivacional de autopromoção e elaboraram, então, um instrumento e validaram-no por meio de análise fatorial e exploratória. Esse trabalho conduziu à identificação de quatro fatores, a saber:

a) Intrínseco - refere-se às metas obtidas pelo conteúdo do próprio trabalho;

b) Extrínseco - refere-se às metas obtidas pelos resultados do próprio trabalho;

c) Social - refere-se à busca de metas relacionais e

d) Prestígio - refere-se à busca de poder e prestígio por meio do trabalho (Porto \& Tamayo, 2008).

Os autores concluíram ser pertinente a estrutura dos valores humanos proposta por Schwartz e propuseram que essa estrutura fosse testada em outras culturas.

A partir desse contexto, Porto e Tamayo (2003) desenvolveram, no Brasil, a Escala de Valores relativos ao Trabalho EVT (Porto \& Tamayo, 2008), detalhada a seguir.

\subsubsection{Escala de valores relativos ao trabalho}

No Brasil, foram desenvolvidas duas escalas para medir esse construto: o Inventário de significado do Trabalho, de Borges (1999), e a escala de Valores relativos ao Trabalho (EVT), constituída por Porto e Tamayo (Porto \& Tamayo, 2008). Ambas foram construídas no contexto brasileiro, validadas por análises fatoriais exploratórias e atingindo índices satisfatórios de precisão.

A EVT considera os

princípios ou crenças sobre metas ou recompensas desejáveis, hierarquicamente organizados, que as pessoas buscam por meio do trabalho e que guiam as suas expectativas sobre resultados e o contexto laboral, bem como o seu comportamento e a escolha de alternativas ao trabalho (Porto \& Tamayo, 2003, p.146). 
A EVT é formada por 45 itens agrupados em quatro fatores, descritos na Figura 5, em que também pode-se verificar a quantidade de itens da escala e o índice de precisão apurado quando de sua validação:

\begin{tabular}{|l|l|l|l|}
\hline \multicolumn{1}{|c|}{ Denominações } & \multicolumn{1}{|c|}{ Definições } & \multicolumn{1}{|c|}{$\begin{array}{c}\text { Itens } \\
\text { precisão }\end{array}$} \\
\hline Realização no trabalho & $\begin{array}{l}\text { Busca de prazer, estimulação e independência de } \\
\text { pensamento e ação no trabalho. }\end{array}$ & 15 & 0,88 \\
\hline Relações sociais & $\begin{array}{l}\text { Busca de relações sociais positivas no trabalho e de } \\
\text { contribuição para a sociedade por meio do trabalho. }\end{array}$ & 12 & 0,88 \\
\hline Prestígio & $\begin{array}{l}\text { Busca do exercício da influência sobre outras pessoas e } \\
\text { do sucesso no trabalho. }\end{array}$ & 11 & 0,87 \\
\hline Estabilidade & $\begin{array}{l}\text { Busca de segurança e estabilidade financeira por meio } \\
\text { trabalho. }\end{array}$ & 7 & 0,81 \\
\hline
\end{tabular}

Figura 5 - Fatores, definições, itens e índices de precisão da EVT

Fonte: Porto \& Tamayo (2008, p. 302).

Tendo em vista sua relação com a escala de valores de Shwartz $(2005 a$, b) e o fato de ter sido a mais recentemente validada, esta escala foi a utilizada na pesquisa deste estudo.

\section{Metodologia}

A pesquisa foi caracterizada nos moldes de um estudo de caso descritivo, de campo e com abordagens quantitativa e qualitativa, caracterizando-se uma triangulação metodológica (Collis \& Hussey, 2005). De acordo com Collis e Hussey (2005, p. 82), o uso de diferentes métodos e técnicas de pesquisa no mesmo estudo é definido como triangulação. Dessa forma, os resultados da pesquisa podem ser potencializados, obtendo maior confiabilidade e validade dos dados a partir de técnicas complementares. Conforme observa Miles (1979), é um erro pensar que os métodos qualitativos se contrapõem às medições quantitativas e, assim, os pesquisadores devem buscar desenvolver combinações. Note-se que, neste artigo, será apresentada a parte quantitativa do estudo.

Yin (2001) avalia estudos de caso como um dos principais recursos para se responder às questões do tipo "como" e "por que". Baseia-se também em Lüdke e André (1986), autores que consideram que, do estudo de caso, emergem novos elementos que contribuem para o entendimento da realidade. Esta pesquisa visou pesquisar o caso de professores de uma instituição de ensino confessional filantrópica.

A caracterização como descritiva deve-se ao alvo da pesquisa que objetiva resolver a seguinte problemática: como se encontram configurados os valores organizacionais e no trabalho de professores de uma instituição de ensino? Dessa forma, propôs-se analisar os valores organizacionais e do trabalho (laborais) dos indivíduos em estudo, para aprofundar nos fatos e fenômenos de sua realidade (Triviños, 1987).

O aspecto relevante para caracterizar esta pesquisa como de campo fundamenta-se no fato de que a mesma ocorreu diretamente no local de trabalho dos sujeitos em questão, em sua unidade estabelecida, o que contribui para explicitar o fenômeno (Vergara, 2009).

A pesquisa quantitativa, segundo Godoy (1995), é aquela cujo objetivo principal é quantificar e mensurar os resultados obtidos, objetivando a precisão sem distorção dos resultados alcançados na fase de interpretação dos resultados, obtendo uma margem segura para realização de inferências. Para atender a esses atributos, a pesquisa contou com a aplicação de questionários para levantamento dos dados referentes aos valores organizacionais e do trabalho, aplicados aos professores em foco, considerando a análise estatística para tratamento desses dados, como detalhado a seguir.

\subsection{Unidades de Análise e de Observação e Sujeitos}

A definição de um grupo de análise fundamenta-se na convicção acerca do que interessa no estudo, ou seja, se é uma organização, um grupo, diferentes subgrupos em uma comunidade ou determinados indivíduos, de acordo com Alves-Mazzoti e Gewandsznajder (1999). No caso da pesquisa realizada, a unidade de análise foi a escola abordada. 
Quanto à unidade de observação, este estudo focalizou os professores da referida escola. Os participantes da pesquisa foram divididos em dois grupos, conforme abordagem de pesquisa a que se submeteram.

Na parte quantitativa, o número total de professores na organização foi levantado junto ao setor de pessoal, sendo eles 650 em todas as unidades. Na unidade pesquisada, eles totalizam 250, para os quais foram entregues o questionário. Deles, 77 devolveram o questionário devidamente preenchido, compondo a amostra da pesquisa, seguindo o critério de acessibilidade (Vergara, 2009), devido ao acesso à organização e à disponibilidade dos empregados para responder o questionário.

\subsection{Técnicas de Coleta de Dados}

Para a coleta de dados, foram utilizados basicamente três instrumentos: levantamento documental, questionário e entrevistas com roteiro semiestruturado, sendo os resultados dos questionários o foco deste artigo.

Inicialmente, a pesquisa exigiu um levantamento documental na própria instituição, com vistas a descrever a organização.

A segunda fase foi marcada pela aplicação do questionário, o qual foi formado por três seções: (1) dados demográficos, funcionais e pessoais; (2) Inventário de Perfis de Valores Organizacionais, IPVO, validado por Oliveira e Tamayo (2004) e extraído de Tamayo (2008, pp. 329-339); e, (3) Escala de Valores relativos ao Trabalho, EVT, validada por Porto e Tamayo (2003) e extraída de Tamayo (2008, p. 304-305). Os questionários são instrumentos cujas questões escritas são apresentadas a seus respondentes, podendo ter estrutura aberta, pouco ou não estruturada, ou fechada-estruturada (Vergara, 2009). No caso desta pesquisa, a estrutura do questionário foi fechada.

\subsection{Técnicas de Análise de Dados}

Os dados oriundos do questionário de coleta foram tabulados e analisados por meio de estatísticas uni e bivariada, sendo que, na primeira, foram apuradas a distribuição de frequência das respostas, bem como as medidas de posicionamento da amostra. De acordo com Collis e Hussey (2005), a medida de posição é um dos procedimentos utilizados para se obter uma redução dos dados, em que se busca a expressão dos valores situados entre os extremos de uma série ou distribuição de dados, nas quais a média e a mediana são as principais medidas usadas para este objetivo. Numa outra perspectiva de análise, foram apurados os percentuais de respondentes por nível de avaliação de cada valor, conforme modelos conceituais adotados. Tal nível de avaliação foi considerado da seguinte forma:

a) Para os valores organizacionais: nível de avaliação baixo (valor frágil, nada importante) os escores abaixo de 2,0; nível de avaliação mediano, os escores entre 2,0 e 3,0; e nível de avaliação elevado (valor forte, importante), escores acima de 3,0;

b) Para os valores do trabalho: nível de avaliação baixo (valor frágil, nada importante) os escores abaixo de 2,5; nível de avaliação mediano, os escores entre 2,5 e 3,5; e nível de avaliação elevado (valor forte, importante), escores acima de 3,5.

$\mathrm{Na}$ segunda parte, a estatística bivariada, foram aplicados testes de comparação (MannWhitney e Kruskall-Wallis) e de correlação (Spearman), de natureza não paramétrica, já que houve violação das condições de normalidade, fato usual em pesquisas que utilizam escalas do tipo Likert. Em tais testes, os níveis de significância adotados foram de 5\% ( $p$-valor abaixo de 0,05).

\section{Apresentação e Análise dos Dados}

A apresentação dos resultados foi estruturada em quatro partes, sendo a primeira destinada ao perfil dos respondentes do questionário e, a segunda, à análise univariada dos valores organizacionais e do trabalho por eles apontados. Na terceira e quarta partes, são apresentados os resultados bivariados, sendo, respectivamente, os frutos dos testes de comparação e os de correlação. 


\subsection{Perfil dos Respondentes do Questionário}

Os questionários foram respondidos por 77 professores. Destes, 66,7\% são do sexo feminino.

A distribuição da faixa etária na amostra pesquisada foi bastante heterogênea: a faixa de 26 a 30 anos comporta a maior concentração de respondentes com $17,5 \%$ do total, pouco mais de $5 \%$ superior às três categorias com o menor percentual de indivíduos: até 25 anos, de 36 a 40 anos e de 46 a 50 anos, todas com $12,3 \%$ do total amostral.

Quanto ao estado civil dos respondentes, a maioria expressiva da amostra é composta por indivíduos casados ou em regime de união estável, enquanto aproximadamente $28 \%$ dos respondentes são solteiros. Uma outra parcela inferior a $10 \%$ é composta por pessoas em outras situações, tais como: desquitadas, divorciadas ou viúvas.

Quanto à escolaridade dos respondentes, foi possível verificar duas categorias que se destacam das demais pelas altas concentrações percentuais observadas: pouco mais de $47 \%$ da amostra possui ensino superior completo e outros 36\%, aproximadamente, possuem especialização. Nota-se ainda que nenhum indivíduo apresenta doutorado concluído e apenas $2 \%$ declararam possuir ensino médio completo.

Note-se que $1,8 \%$ do total de indivíduos declarou ser portador de necessidade especial, o que corresponde, em números absolutos, a apenas uma pessoa dentro da amostra.

Quanto à cor de pele dos respondentes, duas categorias apresentaram frequência relativa nula e duas outras categorias predominaram dentre as demais. Pouco mais de $54 \%$ dos respondentes declararam ser brancos e $36,8 \%$ assinalaram sua cor como parda. O percentual de negros foi de apenas $7 \%$.

Quanto à opção religiosa, 35\%, aproximadamente, declararam-se católicos e pouco mais de $56 \%$, evangélicos. Quanto ao fato de ser praticante ou não da religião mencionada, $87,5 \%$ se declararam praticantes.

Acerca do tempo total de trabalho que os funcionários pesquisados possuem, os resultados correspondem às faixas de maior experiência, ou seja: enquanto mais de $43 \%$ dos indivíduos abordados possuem mais de 20 anos de trabalho, o percentual de funcionários com experiência inferior a 5 anos é de pouco menos de 14\%. Outra categoria com concentração expressiva diz respeito aos respondentes com tempo de trabalho entre 5 e 10 anos $(20,7 \%)$.

Quanto ao tempo em que os pesquisados trabalham na instituição, quase $29 \%$ da amostra já trabalha na instituição de ensino onde foi feito este estudo há mais de 20 anos. Já as três primeiras categorias apresentam distribuição similar e, agregadas, indicam que pouco mais de $41 \%$ dos respondentes que estão na instituição abordada há menos de 5 anos.

Note-se que quase $95 \%$ dos indivíduos pesquisados declararam não exercer função gerencial na referida instituição.

Em relação ao tempo de atuação dos respondentes no cargo atual na instituição de ensino, verificou-se que, aproximadamente, $18 \%$ deles estão no cargo há menos de 1 ano, enquanto pouco menos de $10 \%$ possuem um tempo de atuação no cargo superior a 25 anos.

Quanto ao tempo de atuação na área, os resultados apontam que $14 \%$ dos indivíduos se inserem na última categoria, com experiência na área superior de 25 anos e outros 17,5\% também possuem tempo elevado de atuação (entre 20 e 25 anos). Apenas $7 \%$ dos respondentes declararam exercer profissão na área há menos de 1 ano.

Por fim, as categorias extremas relativas às faixas salariais dos respondentes apresentam frequências relativas baixas ou nulas. A maioria dos professores abordados, cerca de $22 \%$, possui renda entre 7 e 10 salários mínimos. Por outro lado, pouco mais de $17 \%$ dos respondentes recebem menos que 2 salários mínimos.

Assim sendo, a maioria dos respondentes são mulheres, de idades diversas, casadas, com ensino superior completo e especialização, não portadoras de necessidades especiais, com cor de pele branca e parda, católicas e evangélicas praticantes, com mais de 20 anos de experiência de trabalho, há menos de 10 anos na instituição, não exercendo função gerencial, e há menos de um ano no cargo atual e com renda média entre 7 e 10 salários mínimos. 


\subsection{Valores organizacionais e do trabalho, segundo os respondentes}

Quanto aos Valores Organizacionais, observou-se que o bem-estar foi o valor pior avaliado pelos respondentes, visto que apresenta os menores valores de média $(2,3)$, mediana $(2,3)$ e percentis; outro valor que apresentou concentração de dados num patamar inferior é o domínio, com média e mediana equivalentes a 2,8 e percentil 75 , igual a 3,5, indicando que, no mínimo, $75 \%$ dos respondentes conferiram valores inferiores a este na avaliação do referido valor; assim, ambos foram avaliados em nível mediano. Todos os demais valores organizacionais apresentaram concentração de dados num nível superior, com médias e medianas acima de 3,0. (Tabela 1)

\begin{tabular}{|c|c|c|c|c|c|}
\hline \multirow{2}{*}{$\begin{array}{l}\text { Valores } \\
\text { organizacionais }\end{array}$} & \multicolumn{5}{|c|}{ Medidas Descritivas } \\
\hline & Média & $\begin{array}{l}\text { Desvio } \\
\text { Padrão }\end{array}$ & P25 & Mediana & P75 \\
\hline Conformidade & 4,4 & 0,58 & 4,0 & 4,6 & 4,9 \\
\hline Preocupação & a & & & & \\
\hline coletividade & 4,3 & 0,68 & 3,9 & 4,4 & 4,9 \\
\hline Prestígio & 4,2 & 0,66 & 3,9 & 4,3 & 4,8 \\
\hline Realização & 4,1 & 0,70 & 3,7 & 4,2 & 4,8 \\
\hline Autonomia & 3,7 & 0,74 & 3,1 & 4,0 & 4,3 \\
\hline Tradição & 3,4 & 0,63 & 3,0 & 3,4 & 4,0 \\
\hline Domínio & 2,8 & 0,87 & 2,2 & 2,8 & 3,5 \\
\hline Bem-estar & 2,3 & 0,88 & 1,7 & 2,3 & 3,0 \\
\hline
\end{tabular}

Tabela 1 - Estatísticas descritivas dos valores organizacionais Fonte: Dados da pesquisa.

Na sequência, foram apurados os percentuais de respondentes por nível de avaliação de cada um dos valores. Prestígio, conformidade e preocupação com a coletividade foram avaliados por mais de $85 \%$ da amostra em nível elevado, o que indica que esses valores são os mais comungados dentre os professores pesquisados; em sentido inverso, os menos comungados são bem-estar e domínio, como se pode observar na Tabela 2.

\begin{tabular}{|c|c|c|c|}
\hline $\begin{array}{l}\text { Níveis de avaliação } \\
\text { Valores Organizacionals }\end{array}$ & Elevado & Mediano & Baixo \\
\hline Autonomia & 67,9 & 21,4 & 10,7 \\
\hline Bem-estar & 10,7 & 33,9 & 55,4 \\
\hline Realização & 78,6 & 19,6 & 1,8 \\
\hline Domínio & 28,6 & 37,5 & 33,9 \\
\hline Prestígio & 89,3 & 8,9 & 1,8 \\
\hline Conformidade & 87,5 & 10,7 & 1,8 \\
\hline Tradição & 42,9 & 51,8 & 5,4 \\
\hline Preocupação com a coletividade & 85,7 & 14,3 & 0,0 \\
\hline
\end{tabular}

Tabela 2 - Concentração percentual dos respondentes quanto aos níveis de avaliação relativos aos valores organizacionais

Fonte: Dados da pesquisa.

No que diz respeito aos Valores do Trabalho, apenas um apresentou concentração de dados expressivamente inferior à faixa em que se encontram os demais: prestígio (média 2,3, considerada baixa), mostrando que os pesquisados pouco buscam o exercício da influência sobre outras pessoas e o sucesso no trabalho, o que é preocupante, em virtude da profissão abordada, ou seja, professores. Por outro lado, os valores realização no trabalho e relações sociais alcançaram as maiores médias $(4,2$ e 4,1, respectivamente), como se pode observar na Tabela 3:

\begin{tabular}{l|ccccc}
\hline \hline \multirow{2}{*}{ Valores do trabalho } & \multicolumn{4}{|c}{ Medidas Descritivas } \\
\cline { 2 - 5 } & Média & $\begin{array}{c}\text { Desvio } \\
\text { Padrão }\end{array}$ & P25 & Mediana & P75 \\
\hline Realização no trabalho & 4,2 & 0,78 & 3,9 & 4,3 & 4,6 \\
Relações Sociais & 4,1 & 0,78 & 3,8 & 4,3 & 4,8 \\
Estabilidade & 3,9 & 0,94 & 3,3 & 4,1 & 4,7 \\
Prestígio & 2,3 & 0,68 & 1,9 & 2,3 & 2,7 \\
\hline \hline
\end{tabular}

Tabela 3 - Estatísticas descritivas dos valores do trabalho

Fonte: Dados da pesquisa. 
Em seguida, apuraram-se os percentuais de respondentes por nível de avaliação de cada um dos valores. Realização no trabalho e Relações sociais foram avaliados por mais de $80 \%$ da amostra em nível elevado, o que indica que esses valores são os mais comungados dentre os professores pesquisados; em sentido inverso, o menos comungado foi Prestígio, como se pode observar na Tabela 4.

\begin{tabular}{|c|c|c|c|}
\hline $\begin{array}{l}\text { Níveis de avaliação } \\
\text { Valores Organizacionals }\end{array}$ & Elevado & Mediano & Baixo \\
\hline Realização no trabalho & 94,8 & 1,7 & 3,4 \\
\hline $\begin{array}{l}\text { Relações sociais } \\
\text { Prestígio } \\
\text { Estabilidade }\end{array}$ & $\begin{array}{c}82,8 \\
5,2 \\
69,0\end{array}$ & $\begin{array}{l}13,8 \\
29,3 \\
24,1\end{array}$ & $\begin{array}{c}3,4 \\
65,5 \\
6,9\end{array}$ \\
\hline
\end{tabular}

Tabela 4 - Concentração percentual dos respondentes quanto aos níveis de avaliação relativos aos valores do trabalho

Fonte: Dados da pesquisa.

Assim sendo, os professores parecem comungar do prestígio organizacional, mas não do prestígio oriundo do seu próprio trabalho na instituição, sendo esse degrau explicável pela desvalorização crescente do trabalho do professor na sociedade e seus impactos em sua saúde física e mental (Dejours, 1988), a despeito de sua importância social (Tardiff, 2002).

\subsection{Resultados dos Testes de Comparação entre Valores e Dados Sociodemográficos}

Os resultados dessa parte da análise bivariada, ou seja, os testes de comparação, foram variados.

Com relação ao sexo dos respondentes, dos 12 testes realizados, apenas um, relativo ao valor organizacional conformidade, apresentou diferença significativa entre os dados fornecidos pelos indivíduos do sexo masculino e do feminino. O direcionamento do teste aponta que as mulheres fornecem dados mais elevados para a variável conformidade quando comparadas aos homens, ou seja, elas parecem valorizar mais as regras e os modelos de comportamento no ambiente de trabalho e no relacionamento com outras organizações do que seus colegas do sexo masculino. (Tabela 5)

\begin{tabular}{c|c|c|c|c|c}
\hline $\begin{array}{c}\text { Valores } \\
\text { organizacionais e } \\
\text { do trabalho }\end{array}$ & Sexo & Média & $\begin{array}{c}\text { Median } \\
\text { a }\end{array}$ & $\begin{array}{c}\text { P- } \\
\text { valor }\end{array}$ & Conclusão \\
\hline VO-Conformidade & $\begin{array}{c}\text { Masculino } \\
\text { Feminino }\end{array}$ & $\begin{array}{c}4,1 \\
4,5\end{array}$ & $\begin{array}{c}4,1 \\
4,6\end{array}$ & 0,037 & $\begin{array}{c}\text { Há diferença significativa } \\
\text { entre as médias }\end{array}$ \\
\hline
\end{tabular}

Tabela 5 - Resultado significativo do testes de comparação de médias para os valores organizacionais e do trabalho em função do sexo Fonte: Dados da pesquisa.

Quanto à faixa etária, nenhum p-valor encontrado se situou abaixo do nível de significância de $5 \%$.

Logo, pode-se concluir que a faixa etária não é um fator de influência expressiva na avaliação dos respondentes quanto aos valores organizacionais e do trabalho, ou seja, os dados fornecidos pelos indivíduos de diferentes faixas etárias não apresentam diferença estatisticamente significativa.

\begin{tabular}{|c|c|c|c|c|c|}
\hline $\begin{array}{c}\text { Valores } \\
\text { organizacionais } \\
\text { e do trabalho }\end{array}$ & Estado civil & $\begin{array}{c}\text { Médi } \\
\text { a }\end{array}$ & $\begin{array}{c}\text { Median } \\
a\end{array}$ & $\begin{array}{c}\text { P- } \\
\text { valor }\end{array}$ & Conclusão \\
\hline VT - Estabilidade & $\begin{array}{c}\text { Solteiro } \\
\text { casado/união estável } \\
\text { outro }\end{array}$ & $\begin{array}{l}4,3 \\
3,7 \\
4,7\end{array}$ & $\begin{array}{l}4,4 \\
4,0 \\
4,9\end{array}$ & 0,013 & $\begin{array}{c}\text { Há diferença } \\
\text { significativa entre } \\
\text { as médias }\end{array}$ \\
\hline
\end{tabular}

Tabela 6 - Resultado significativo do testes de comparação de médias para os valores organizacionais e do trabalho em função do estado civil

Fonte: Dados da pesquisa.

No que tange ao Estado Civil, apenas um p-valor encontrado ficou abaixo do nível de significância de 5\%, relativo ao valor do trabalho Estabilidade (Tabela 6). O direcionamento do teste aponta níveis de dados bastante díspares para as três categorias de estado civil em questão, sendo 
os respondentes casados ou em união estável responsáveis pelos dados expressivamente mais baixos, indicando que esse grupo busca por segurança e por ordem na vida por meio do trabalho, de modo a possibilitar suprir materialmente as necessidades pessoais, de maneira menos intensa que os demais.

Com relação à escolaridade, apenas o valor Tradição apresentou p-valor significativo e o direcionamento do teste indicou que os professores com ensino superior incompleto apontaram os maiores dados fornecidos, parecendo valorizarem os costumes e práticas consagradas mais intensamente que os demais grupos de respondentes de nível de escolaridade diferentes. (Tabela 7)

\begin{tabular}{|c|c|c|c|c|c|}
\hline $\begin{array}{c}\text { Valores } \\
\text { organizacionais } \\
\text { e do trabalho }\end{array}$ & Escolaridade & $\begin{array}{l}\text { Médi } \\
\text { a }\end{array}$ & $\begin{array}{c}\text { Median } \\
\text { a }\end{array}$ & $\begin{array}{c}\text { P- } \\
\text { valor }\end{array}$ & Conclusão \\
\hline \multirow{6}{*}{ VO - Tradição } & Ensino médio completo & 2,8 & 2,8 & \multirow{6}{*}{0,022} & \multirow{6}{*}{$\begin{array}{c}\text { Há } \\
\text { diferença } \\
\text { significativa } \\
\text { entre as } \\
\text { médias }\end{array}$} \\
\hline & Ensino superior incompleto & 4,1 & 4,1 & & \\
\hline & Ensino superior completo & 3,6 & 3,8 & & \\
\hline & Especialização & 3,3 & 3,2 & & \\
\hline & Mestrado & 3,2 & 2,9 & & \\
\hline & Doutorado & - & - & & \\
\hline
\end{tabular}

Tabela 7 - Resultado significativo do testes de comparação de médias para os valores organizacionais e do trabalho em função da escolaridade

Fonte: Dados da pesquisa.

Quanto ao fato de ser, ou não, portador de necessidade especial (PNE), os testes não indicaram qualquer diferença significativa entre os grupos. O mesmo ocorreu com os grupos formados por afirmação de diferentes cores de pele, na qual não se percebeu nenhum resultado de teste abaixo de 0,05 .

Quanto à Religião que professam, os grupos apresentaram apenas um resultado significativamente diferente ( $p$-valor igual a 0,029 ), relativo ao valor Tradição. No entanto, é importante ressaltar que o resultado possivelmente foi influenciado pelo reduzido número de representantes em três categorias (um indivíduo budista, um respondente sem religião e dois outros pertencentes à categoria "outra religião"). Observou-se que apenas os valores relativos a essas três categorias são expressivamente díspares dos demais, da seguinte forma: o respondente budista apresentou os dados mais elevados para Tradição, enquanto as duas demais categorias ("sem religião" e "outra") mostraram os valores mais baixos. (Tabela 8)

\begin{tabular}{|c|c|c|c|c|c|}
\hline $\begin{array}{c}\text { Valores } \\
\text { organizacionais } \\
\text { e do trabalho }\end{array}$ & Religião & $\begin{array}{l}\text { Médi } \\
\text { a }\end{array}$ & $\begin{array}{c}\text { Median } \\
\quad \mathrm{a}\end{array}$ & P-valor & Conclusão \\
\hline \multirow{6}{*}{ VO - Tradição } & católica & 3,6 & 3,8 & \multirow{6}{*}{0,029} & \multirow{6}{*}{$\begin{array}{c}\text { Há diferença } \\
\text { significativa entre as } \\
\text { médias }\end{array}$} \\
\hline & evangélica & 3,4 & 3,8 & & \\
\hline & espírita & & & & \\
\hline & $\begin{array}{c}\text { budista } \\
\text { candomblé }\end{array}$ & 4,2 & 4,2 & & \\
\hline & outra & 2,2 & 2,2 & & \\
\hline & sem religião & 2,8 & 2,8 & & \\
\hline
\end{tabular}

Tabela 8 - Resultado significativo do testes de comparação de médias para os valores organizacionais e do trabalho em função da religião

Fonte: Dados da pesquisa.

Tendo em vista o contexto de escola confessional e filantrópica da instituição abordada e a importância dessa diferenciação em termos de religião para esta pesquisa, cujo tema central são os valores das pessoas, pode ser precipitado tirar conclusões a esse respeito, diante dos indícios apresentados. Nota-se que, considerando-se o fato de o respondente ser, ou não, praticante da religião que professa, nenhum dos testes realizados para verificar possíveis diferenças entre esses dois grupos (praticantes, P, ou não praticantes, NP) apontou resultado significativo que permita afirmar qualquer diferença entre eles.

Acerca de possíveis diferenças entre os respondentes com variados tempos totais de trabalho, nenhum p-valor apurado por meio dos testes foi significativo, o que indica que a experiência total de trabalho dos respondentes não se apresenta como fator de influência expressiva ao se avaliar os valores organizacionais e do trabalho. 
O mesmo resultado foi observado considerando-se o tempo de trabalho na instituição, isto é, como nenhum p-valor foi inferior a 0,05 , conclui-se que os respondentes com diferentes faixas de experiência dentro da instituição pesquisada não avaliam de forma diferente os valores organizacionais e do trabalho.

Do mesmo modo que nos testes anteriormente apresentados, o tempo de atuação na área também não parece significativo elemento de diferenciação entre os grupos segmentados com base nesse dado funcional.

Fato semelhante também ocorreu quando da diferenciação dos respondentes por tempo de exercício no cargo atual, não se observando diferença estatisticamente significativa nesse sentido.

O fato de exercer, ou não, uma função gerencial, também não se mostrou como influente na opinião dos dois grupos confrontados, na qual todos os resultados dos testes foram superiores a 0,05 .

Quanto aos diferentes níveis salariais que os respondentes recebem, em dois casos, os pvalores encontrados se situam abaixo do nível de significância de $5 \%$ e o direcionamento dos testes apontam exatamente a mesma tendência para ambos os valores organizacionais considerados, que foram a autonomia e a realização. Verificou-se a presença de valores expressivamente mais baixos fornecidos pelo grupo de respondentes pertencentes às três primeiras faixas salariais (que recebem até 3 salários mínimos, SM) para o valor autonomia. Já os dados obtidos dos respondentes que ganham entre 3 e 10 SM são significativamente mais elevados. Curiosamente, os três únicos respondentes, que possuem a maior faixa salarial e ganham entre 10 e 20 SM, forneceram valores muito similares aos verificados para os respondentes das três primeiras categorias (até 3 SM). (Tabela 9)

\begin{tabular}{|c|c|c|c|c|c|}
\hline $\begin{array}{c}\text { Valores } \\
\text { organizacionais e } \\
\text { do trabalho }\end{array}$ & Salário & $\begin{array}{l}\text { Médi } \\
\text { a }\end{array}$ & $\begin{array}{c}\text { Median } \\
a\end{array}$ & P-valor & Conclusão \\
\hline \multirow{9}{*}{ VO - Autonomia } & até 1 salário mínimo SM & 3,1 & 3,1 & \multirow{9}{*}{0,016} & \multirow{9}{*}{$\begin{array}{c}\text { Há } \\
\text { diferença } \\
\text { significativ } \\
\text { a entre as } \\
\text { médias }\end{array}$} \\
\hline & de 1 SM a 2 SM & 3,2 & 3,3 & & \\
\hline & de 2 SM a 3 SM & 3,3 & 3,5 & & \\
\hline & de 3 SM a 4 SM & 4,2 & 4,2 & & \\
\hline & de 4 SM a 5 SM & 3,7 & 3,8 & & \\
\hline & de 5 SM a 7 SM & 4,1 & 4,3 & & \\
\hline & de 7 SM a 10 SM & 3,8 & 4,0 & & \\
\hline & de 10 SM a 20 SM & 3,1 & 2,8 & & \\
\hline & acima de 20 SM & - & - & & \\
\hline \multirow{9}{*}{ VO - Realização } & até 1 salário mínimo SM & 3,6 & 3,6 & \multirow{9}{*}{0,012} & \multirow{9}{*}{$\begin{array}{c}\text { Há } \\
\text { diferença } \\
\text { significativ } \\
\text { a entre as } \\
\text { médias }\end{array}$} \\
\hline & de 1 SM a 2 SM & 3,9 & 3,8 & & \\
\hline & de 2 SM a 3 SM & 3,6 & 3,9 & & \\
\hline & de 3 SM a 4 SM & 4,8 & 4,8 & & \\
\hline & de 4 SM a 5 SM & 4,2 & 4,1 & & \\
\hline & de 5 SM a 7 SM & 4,3 & 4,4 & & \\
\hline & de 7 SM a 10 SM & 4,1 & 4,2 & & \\
\hline & de 10 SM a 20 SM & 3,7 & 3,4 & & \\
\hline & acima de 20 SM & . & 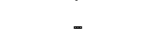 & & \\
\hline
\end{tabular}

Tabela 9 - Resultado significativo do testes de comparação de médias para os valores organizacionais e do trabalho em função da faixa salarial

Fonte: Dados da pesquisa.

Assim sendo, os testes de comparação apontaram diferenças significativas que envolviam sexo ("conformidade"), estado civil ("estabilidade"), escolaridade ("tradição"), religião ("tradição") e renda ("autonomia" e "realização" no trabalho).

\subsection{Resultados dos testes de correlação entre valores e dados sociodemográficos}

Foram realizados 108 testes com cruzamentos entre as variáveis demográficas e profissionais e os valores organizacionais e do trabalho. Em apenas 4 casos, o p-valor calculado foi inferior ao nível de significância de 5\%, apontando tendência estatisticamente significativa. Esses casos estão destacados em negrito na Tabela 10.

Na coluna relativa ao valor organizacional "bem-estar", é possível verificar que três variáveis apresentam coeficientes de correlação significativos e positivos, quais sejam: as mulheres tendem a 
Valores organizacionais e do trabalho: um estudo com professores de uma escola filantrópica e confessional de Belo Horizonte (MG)

fornecer valores significativamente superiores para esse valor quando comparadas aos homens; respondentes com maior experiência tendem a atribuir escores mais elevados que os menos experientes; e respondentes com maior experiência na instituição tendem a expressar escores mais elevados que os menos experientes.

\begin{tabular}{|c|c|c|c|c|c|c|c|c|c|c|c|c|}
\hline \multirow{2}{*}{$\begin{array}{c}\text { Variávei } \\
\text { s }\end{array}$} & \multicolumn{4}{|c|}{ Valores do Trabalho } & \multicolumn{8}{|c|}{ Valores Organizacionais } \\
\hline & RT & RP & PT & $E$ & $A$ & $\mathrm{BE}$ & $\mathbf{R}$ & $\mathrm{D}$ & PO & $\mathrm{C}$ & $T$ & PC \\
\hline Sexo & $\begin{array}{c}0,228 \\
(0,09 \\
4)\end{array}$ & $\begin{array}{c}- \\
0,022 \\
(0,87 \\
3)\end{array}$ & $\begin{array}{c}0,252 \\
(0,06 \\
4)\end{array}$ & $\begin{array}{c}0,114 \\
(0,40 \\
8)\end{array}$ & $\begin{array}{c}0,069 \\
(0,61 \\
6)\end{array}$ & $\begin{array}{c}0,28 \\
4 * \\
(0,0 \\
36)\end{array}$ & $\begin{array}{c}- \\
0,017 \\
(0,90 \\
1)\end{array}$ & $\begin{array}{c}0,097 \\
(0,48 \\
1)\end{array}$ & $\begin{array}{c}- \\
0,117 \\
(0,38 \\
5)\end{array}$ & $\begin{array}{c}- \\
0,028 \\
(0,83 \\
4)\end{array}$ & $\begin{array}{c}- \\
0,154 \\
(0,25 \\
2)\end{array}$ & $\begin{array}{c}- \\
0,118 \\
(0,38 \\
2)\end{array}$ \\
\hline FE & $\begin{array}{c}(0,46 \\
0)\end{array}$ & $\begin{array}{c}- \\
0,037 \\
(0,79 \\
0)\end{array}$ & $\begin{array}{c}0,014 \\
(0,92 \\
0)\end{array}$ & $\begin{array}{c}0,002 \\
(0,98 \\
8)\end{array}$ & $\begin{array}{c}0,018 \\
(0,89 \\
8)\end{array}$ & $\begin{array}{c}0,139 \\
(0,31 \\
1)\end{array}$ & $\begin{array}{c}- \\
0,174 \\
(0,20 \\
3)\end{array}$ & $\begin{array}{c}0,001 \\
(0,99 \\
3)\end{array}$ & $\begin{array}{c}- \\
0,088 \\
(0,51 \\
5)\end{array}$ & $\begin{array}{c}- \\
0,036 \\
(0,79 \\
1)\end{array}$ & $\begin{array}{c}- \\
0,136 \\
(0,31 \\
3)\end{array}$ & $\begin{array}{c}- \\
0,064 \\
(0,63 \\
8)\end{array}$ \\
\hline Esc & $\begin{array}{c}- \\
0,016 \\
(0,90 \\
8)\end{array}$ & $\begin{array}{c}- \\
0,008 \\
(0,95 \\
3)\end{array}$ & $\begin{array}{c}0,037 \\
(0,79 \\
3)\end{array}$ & $\begin{array}{c}- \\
0,114 \\
(0,41 \\
5)\end{array}$ & $\begin{array}{c}- \\
0,003 \\
(0,98 \\
4)\end{array}$ & $\begin{array}{c}- \\
0,203 \\
(0,14 \\
4)\end{array}$ & $\begin{array}{c}- \\
0,35 \\
9 * \\
(0,0 \\
08)\end{array}$ & $\begin{array}{c}- \\
0,013 \\
(0,92 \\
6)\end{array}$ & $\begin{array}{c}0,061 \\
(0,66 \\
4)\end{array}$ & $\begin{array}{c}0,020 \\
(0,88 \\
8)\end{array}$ & $\begin{array}{c}0,065 \\
(0,64 \\
3)\end{array}$ & $\begin{array}{c}0,039 \\
(0,78 \\
4)\end{array}$ \\
\hline TTT & $\begin{array}{c}0,197 \\
(0,14 \\
5)\end{array}$ & $\begin{array}{c}- \\
0,111 \\
(0,41 \\
7)\end{array}$ & $\begin{array}{c}0,125 \\
(0,35 \\
7)\end{array}$ & $\begin{array}{c}- \\
0,004 \\
(0,97 \\
9)\end{array}$ & $\begin{array}{c}0,066 \\
(0,62 \\
8)\end{array}$ & $\begin{array}{c}0,27 \\
1 * \\
(0,0 \\
43)\end{array}$ & $\begin{array}{c}- \\
0,126 \\
(0,35 \\
5)\end{array}$ & $\begin{array}{c}0,083 \\
(0,54 \\
2)\end{array}$ & $\begin{array}{c}0,064 \\
(0,63 \\
4)\end{array}$ & $\begin{array}{c}0,073 \\
(0,58 \\
6)\end{array}$ & $\begin{array}{c}0,062 \\
(0,64 \\
6)\end{array}$ & $\begin{array}{c}0,006 \\
(0,96 \\
3)\end{array}$ \\
\hline TTI & $\begin{array}{c}0,222 \\
(0,10 \\
1)\end{array}$ & $\begin{array}{c}- \\
0,110 \\
(0,42 \\
2)\end{array}$ & $\begin{array}{c}0,155 \\
(0,25 \\
4)\end{array}$ & $\begin{array}{c}0,052 \\
(0,70 \\
2)\end{array}$ & $\begin{array}{c}0,112 \\
(0,41 \\
0)\end{array}$ & $\begin{array}{c}0,27 \\
7 * \\
(0,0 \\
39)\end{array}$ & $\begin{array}{c}- \\
0,157 \\
(0,24 \\
7)\end{array}$ & $\begin{array}{c}0,043 \\
(0,75 \\
2)\end{array}$ & $\begin{array}{c}- \\
0,125 \\
(0,35 \\
0)\end{array}$ & $\begin{array}{c}- \\
0,120 \\
(0,37 \\
1)\end{array}$ & $\begin{array}{c}- \\
0,119 \\
(0,37 \\
3)\end{array}$ & $\begin{array}{c}- \\
0,077 \\
(0,56 \\
7)\end{array}$ \\
\hline unc & $\begin{array}{c}- \\
0,237 \\
(0,08 \\
5)\end{array}$ & $\begin{array}{c}0,154 \\
(0,26 \\
8)\end{array}$ & $\begin{array}{c}- \\
0,243 \\
(0,07 \\
7)\end{array}$ & $\begin{array}{c}- \\
0,005 \\
(0,97 \\
0)\end{array}$ & $\begin{array}{c}- \\
0,144 \\
(0,29 \\
8)\end{array}$ & $\begin{array}{c}- \\
0,165 \\
(0,23 \\
4)\end{array}$ & $\begin{array}{c}0,042 \\
(0,76 \\
4)\end{array}$ & $\begin{array}{c}- \\
0,055 \\
(0,69 \\
4)\end{array}$ & $\begin{array}{c}- \\
0,175 \\
(0,20 \\
1)\end{array}$ & $\begin{array}{c}- \\
0,233 \\
(0,08 \\
7)\end{array}$ & $\begin{array}{c}- \\
0,083 \\
(0,54 \\
5)\end{array}$ & $\begin{array}{c}- \\
0,215 \\
(0,11 \\
5)\end{array}$ \\
\hline TAC & $\begin{array}{c}0,199 \\
(0,17 \\
1)\end{array}$ & $\begin{array}{c}- \\
0,097 \\
(0,50 \\
7)\end{array}$ & $\begin{array}{c}0,113 \\
(0,43 \\
8)\end{array}$ & $\begin{array}{c}0,053 \\
(0,71 \\
9)\end{array}$ & $\begin{array}{c}0,035 \\
(0,81 \\
2)\end{array}$ & $\begin{array}{c}0,217 \\
(0,13 \\
4)\end{array}$ & $\begin{array}{c}0,164 \\
(0,25 \\
9)\end{array}$ & $\begin{array}{c}0,001 \\
(0,99 \\
4)\end{array}$ & $\begin{array}{c}0,130 \\
(0,36 \\
4)\end{array}$ & $\begin{array}{c}- \\
0,142 \\
(0,32 \\
0)\end{array}$ & $\begin{array}{c}- \\
0,196 \\
(0,16 \\
7)\end{array}$ & $\begin{array}{c}0,016 \\
(0,91 \\
3)\end{array}$ \\
\hline TAA & $\begin{array}{c}0,217 \\
(0,11 \\
1)\end{array}$ & $\begin{array}{c}0,035 \\
(0,80 \\
0)\end{array}$ & $\begin{array}{c}0,123 \\
(0,37 \\
2)\end{array}$ & $\begin{array}{c}- \\
0,083 \\
(0,54 \\
8)\end{array}$ & $\begin{array}{c}- \\
0,007 \\
(0,95 \\
9)\end{array}$ & $\begin{array}{c}0,134 \\
(0,32 \\
9)\end{array}$ & $\begin{array}{c}- \\
0,162 \\
(0,23 \\
7)\end{array}$ & $\begin{array}{c}0,058 \\
(0,67 \\
2)\end{array}$ & $\begin{array}{c}- \\
0,124 \\
(0,35 \\
9)\end{array}$ & $\begin{array}{c}- \\
0,037 \\
(0,78 \\
7)\end{array}$ & $\begin{array}{c}- \\
0,187 \\
(0,16 \\
3)\end{array}$ & $\begin{array}{c}- \\
0,097 \\
(0,47 \\
1)\end{array}$ \\
\hline Sal & $\begin{array}{c}0,229 \\
(0,08 \\
9)\end{array}$ & $\begin{array}{c}0,199 \\
(0,14 \\
2)\end{array}$ & $\begin{array}{c}0,071 \\
(0,60 \\
4)\end{array}$ & $\begin{array}{c}- \\
0,194 \\
(0,15 \\
3)\end{array}$ & $\begin{array}{c}- \\
0,072 \\
(0,59 \\
9)\end{array}$ & $\begin{array}{c}- \\
0,099 \\
(0,46 \\
7)\end{array}$ & $\begin{array}{c}- \\
0,188 \\
(0,16 \\
6) \\
\end{array}$ & $\begin{array}{c}0,105 \\
(0,44 \\
0)\end{array}$ & $\begin{array}{c}0,024 \\
(0,85 \\
9)\end{array}$ & $\begin{array}{c}0,094 \\
(0,48 \\
2)\end{array}$ & $\begin{array}{c}0,122 \\
(0,36 \\
3)\end{array}$ & $\begin{array}{c}0,096 \\
(0,47 \\
4)\end{array}$ \\
\hline
\end{tabular}

Tabela 10 - Resultados dos testes de correlação entre variáveis sócio-demográficas e valores organizacionais e do trabalho

Fonte: Dados da pesquisa.

Nota: RT: Realização Trabalho; RS: Relações Sociais; PT: Prestígio (valor no trabalho); E: Estabilidade; A: Autonomia; BE: Bem-Estar; R: Realização; D: Domínio; PO: Prestígio (valor organizacional); C: Conformidade; T: Tradição; PCC: Preocupação com a Coletividade;

FE: faixa etária; Esc: escolaridade; TT: tempo total de trabalho; TTI: tempo de trabalho na instituição; FG: função gerencial; TAC: tempo no cargo atual; TTA: tempo na área; Sal: faixa salarial.

Na coluna relativa ao valor organizacional "realização", foi possível observar um coeficiente rho significativo (menor que 0,05) e negativo, indicando que os respondentes com menor nível de escolaridade tendem a fornecer valores de avaliação mais elevados para tal valor.

Foram também efetuados 66 testes de correlações entre os valores organizacionais e os do trabalho, dos quais 32 apresentam coeficientes de correlação significativos, sendo todos eles (6 de 6), cruzando os valores do trabalho entre si, 16 (de 28), cruzando os valores organizacionais entre si, e 10 deles (de 32), cruzando valores organizacionais com valores do trabalho. Todos os resultados significativos estão destacados em negrito na Tabela 11. 


\begin{tabular}{|c|c|c|c|c|c|c|c|c|c|c|c|}
\hline \multirow{2}{*}{ Valores } & \multicolumn{4}{|c|}{ Do Trabalho } & \multicolumn{7}{|c|}{ Organizacionais } \\
\hline & RT & RP & PT & $E$ & $A$ & BE & R & $\mathrm{D}$ & PO & $C$ & $\bar{T}$ \\
\hline RP & $\begin{array}{c}0,722 * \\
(0,000)\end{array}$ & & $*$ & $*$ & * & * & * & * & $*$ & $*$ & * \\
\hline PT & $\begin{array}{c}0,545^{*} \\
(0,000)\end{array}$ & $\begin{array}{c}0,348 * \\
(0,007)\end{array}$ & & $*$ & * & * & * & * & * & $*$ & $*$ \\
\hline$E$ & $\begin{array}{c}0,657 * \\
(0,000)\end{array}$ & $\begin{array}{c}0,532 * \\
(0,000)\end{array}$ & $\begin{array}{c}0,388 * \\
(0,003)\end{array}$ & & * & * & * & * & * & $*$ & * \\
\hline $\bar{A}$ & $\begin{array}{c}0,240 \\
(0,074)\end{array}$ & $\begin{array}{c}0,273^{*} \\
(0,042)\end{array}$ & $\begin{array}{c}0,052 \\
(0,704)\end{array}$ & $\begin{array}{c}0,136 \\
(0,319)\end{array}$ & & $*$ & * & $*$ & $*$ & $*$ & $*$ \\
\hline BE & $\begin{array}{c}-0,008 \\
(0,955)\end{array}$ & $\begin{array}{c}0,100 \\
(0,463)\end{array}$ & $\begin{array}{c}0,023 * \\
(0,866)\end{array}$ & $\begin{array}{c}-0,190 \\
(0,161)\end{array}$ & $\begin{array}{c}0,470 * \\
(0,000)\end{array}$ & & $*$ & * & $*$ & $*$ & $*$ \\
\hline $\mathbf{R}$ & $\begin{array}{c}0,314 * \\
(0,018)\end{array}$ & $\begin{array}{c}0,328 * \\
(0,014)\end{array}$ & $\begin{array}{c}0,154 \\
(0,257)\end{array}$ & $\begin{array}{c}0,092 \\
(0,500)\end{array}$ & $\begin{array}{c}0,892 * \\
(0,000)\end{array}$ & $\begin{array}{c}0,408 * \\
(0,002)\end{array}$ & & $*$ & $*$ & $*$ & $*$ \\
\hline D & $\begin{array}{c}0,044 \\
(0,746)\end{array}$ & $\begin{array}{c}0,051 \\
(0,709)\end{array}$ & $\begin{array}{c}-0,076 \\
(0,577)\end{array}$ & $\begin{array}{c}0,086 \\
(0,528)\end{array}$ & $\begin{array}{c}0,241 \\
(0,073)\end{array}$ & $\begin{array}{c}0,253 \\
(0,060)\end{array}$ & $\begin{array}{c}0,189 \\
(0,163)\end{array}$ & & $*$ & $*$ & $*$ \\
\hline PO & $\begin{array}{c}0,307^{*} \\
(0,021)\end{array}$ & $\begin{array}{c}0,382 * \\
(0,004)\end{array}$ & $\begin{array}{c}0,107 \\
(0,435)\end{array}$ & $\begin{array}{c}0,125 \\
(0,358)\end{array}$ & $\begin{array}{c}0,506 * \\
(0,000)\end{array}$ & $\begin{array}{c}0,183 \\
(0,177)\end{array}$ & $\begin{array}{c}0,558 * \\
(0,000)\end{array}$ & $\begin{array}{c}0,397 * \\
(0,002)\end{array}$ & & $*$ & $*$ \\
\hline C & $\begin{array}{c}0,320 * \\
(0,016)\end{array}$ & $\begin{array}{c}0,385^{*} \\
(0,003)\end{array}$ & $\begin{array}{c}0,151 \\
(0,266)\end{array}$ & $\begin{array}{c}0,263 \\
(0,050)\end{array}$ & $\begin{array}{c}0,452 * \\
(0,000)\end{array}$ & $\begin{array}{c}0,014 \\
(0,916)\end{array}$ & $\begin{array}{c}0,435^{*} \\
(0,001)\end{array}$ & $\begin{array}{c}0,405^{*} \\
(0,002)\end{array}$ & $\begin{array}{c}0,569 * \\
(0,000)\end{array}$ & & * \\
\hline $\mathrm{T}$ & $\begin{array}{c}0,064 \\
(0,637)\end{array}$ & $\begin{array}{c}0,065 \\
(0,635)\end{array}$ & $\begin{array}{c}0,182 \\
(0,178)\end{array}$ & $\begin{array}{c}0,207 \\
(0,126)\end{array}$ & $\begin{array}{c}-0,090 \\
(0,511)\end{array}$ & $\begin{array}{c}0,043 \\
(0,755)\end{array}$ & $\begin{array}{c}-0,166 \\
(0,220)\end{array}$ & $\begin{array}{c}0,361 \\
(0,006)\end{array}$ & $\begin{array}{c}0,053 \\
(0,700)\end{array}$ & $\begin{array}{c}0,337 * \\
(0,011)\end{array}$ & \\
\hline PCC & $\begin{array}{c}0,213 \\
(0,114) \\
\end{array}$ & $\begin{array}{c}0,390 * \\
(0,003)\end{array}$ & $\begin{array}{c}0,104 \\
(0,445) \\
\end{array}$ & $\begin{array}{c}0,043^{*} \\
(0,752) \\
\end{array}$ & $\begin{array}{c}0,610 * \\
(0,000)\end{array}$ & $\begin{array}{c}0,279 * \\
(0,037) \\
\end{array}$ & $\begin{array}{c}0,608 * \\
(0,000)\end{array}$ & $\begin{array}{c}0,094 \\
(0,490) \\
\end{array}$ & $\begin{array}{c}0,483^{*} \\
(0,000)\end{array}$ & $\begin{array}{c}0,392 * \\
(0,003)\end{array}$ & $\begin{array}{c}-0,151 \\
(0,267) \\
\end{array}$ \\
\hline
\end{tabular}

Tabela 11 - Resultados dos testes de correlação entre valores organizacionais e valores do

trabalho

Fonte: Dados da pesquisa.

Nota: RT: Realização Trabalho; RS: Relações Sociais; PT: Prestígio (valor no trabalho); E: Estabilidade; A: Autonomia; BE: Bem-Estar; R: Realização; D: Domínio; PO: Prestígio (valor organizacional); C: Conformidade; T: Tradição; PCC: Preocupação com a Coletividade.

Note-se que, em todos os casos, o valor de rho é positivo, indicando correlação de ordem diretamente proporcional. Portanto, uma análise individual dos casos significativos torna-se desnecessária, visto que, em todos eles, observou-se uma tendência de correspondência similar, ou seja, dados elevados em um valor variável são sempre acompanhados por escores altos, seguindose a mesma tendência para os dados menos expressivos.

A partir desses resultados, foram estruturadas as seguintes considerações finais.

\section{Considerações Finais e Recomendações}

Este estudo teve como objetivo geral analisar como se encontram configurados os valores organizacionais e do trabalho de professores, na percepção deles próprios.

O referencial teórico foi pautou-se em valores, de modo geral, aprofundando nos valores organizacionais e nos do trabalho. Considerando-se a operacionalização da pesquisa, os modelos conceituais que sustentam o Inventário de Perfis de Valores, construído e validado por Oliveira e Tamayo (2004), e a Escala de Valores relativos ao Trabalho, construída e validada por Porto e Tamayo (2003), foram detalhados, tendo em vista sua adoção para fins da pesquisa realizada.

Tal pesquisa de campo, de cunho descritivo e nos moldes de um estudo de caso, foi realizada em uma instituição de ensino filantrópica e confessional, localizada em Belo Horizonte (MG), focalizando professores que atuavam do ensino fundamental ao ensino médio. Foi realizada uma triangulação metodológica, porém apenas a parte quantitativa do estudo foi apresentada neste artigo, a qual contou com os resultados da aplicação de 77 questionários. Os dados foram analisados a partir dos resultados estatísticos uni e bivariados. O critério para a escolha da instituição e dos pesquisados foi a acessibilidade.

No que diz respeito aos valores do trabalho (primeiro objetivo específico), resultados positivos foram identificadas no que diz respeito aos valores "realização", "relações sociais" e "estabilidade"; em sentido inverso, os dados relativos ao valor "prestígio" no âmbito do trabalho, foram os mais tímidos na avaliação dos pesquisados, o que pode estar refletindo a precarização do trabalho do professor no espaço observado.

Quanto aos valores organizacionais (segundo objetivo específico), apuraram-se resultados positivos no que tange à "autonomia", "realização", "conformidade" e "preocupação com a 
Valores organizacionais e do trabalho: um estudo com professores de uma escola filantrópica e confessional de Belo Horizonte (MG)

coletividade". Por outro lado, os valores "bem-estar", "domínio", "prestígio" e "tradição" tiveram resultados menos expressivos.

Nessa parte da análise (terceiro objetivo específico), os testes de correlação apontaram diversas tendências e os testes de comparação apontaram diferenças significativas em cinco casos, quais sejam:

a) mulheres apresentaram escores significativamente maiores que os homens para o valor organizacional "conformidade";

b) solteiros e em "outro" estado civil apresentaram escores significativamente maiores que os casados para o valor do trabalho "estabilidade";

c) professores com ensino superior incompleto apresentaram escores significativamente maiores que os demais para o valor organizacional "tradição";

d) o professor que se declarou budista apresentou escore significativamente maior que os demais para o valor organizacional "tradição", mas, como se trata de apenas um professor, esse resultado deve ser observado com cautela;

e) professores com faixa salarial de até 3 salários mínimos (SM) forneceram escores expressivamente mais baixos para o valor organizacional "autonomia"; e professores que ganham entre 3 e 10 SM apontaram escores significativamente mais elevados que os demais para o valor organizacional "realização".

Assim como as disparidades encontradas em relação aos valores organizacionais mencionadas anteriormente, os resultados significativos dos testes de comparação carecem de aprofundamento em pesquisas posteriores, o que foi realizado na parte qualitativa do estudo, não retratada neste artigo.

Não perdendo de vista as contribuições do estudo aqui realizado (tema pouco pesquisado no Brasil; primeira parte de uma triangulação metodológica; resultados que apontam similaridades e disparidades) e suas limitações (dificuldade de generalização dos dados tendo em vista a realização de um estudo único de caso, em um colégio particular), pode-se sugerir a realização de outras investigações nos seguintes sentidos: ampliar a pesquisa para outras instituições, públicas e privadas; para outros níveis de ensino (superior, por exemplo) e promovendo uma diferenciação entre os professores que atuam em níveis diferentes; incluir outras temáticas comportamentais cujas categorias de análise perpassaram os relatos dos entrevistados, como é o caso de valores pessoais, estresse ocupacional, síndrome de burnout, qualidade de vida no trabalho, justiça organizacional e atitudes retaliatórias, dentre outras. Além disso, as questões relativas aos gêneros e à religião, observadas nos resultados dos testes de comparação, também indicam a necessidade de se ousar tratar de questões relativas à diversidade e às diferenças nos estudos comportamentais.

Tais sugestões visam possíveis comparações e generalizações, contribuindo para construir relacionamentos mais saudáveis e políticas e práticas de gestão mais condizentes com os valores dos indivíduos que trabalham em determinados espaços laborais, de modo a respeitá-los, senão na sua integridade, pelo menos em boa parte dos princípios que regem o comportamento das pessoas.

Por fim, espera-se que este estudo permita aos sujeitos que foram protagonistas da pesquisa, bem como a outros indivíduos que nela se vejam retratados, a possibilidade de se valerem dessa reflexão para obterem uma auto-imagem positiva de si mesmos à luz dos dados aqui dispostos e que, na interação entre profissionais e instituições, possa se buscar e encontrar uma congruência de objetivos fundamentada pelos valores organizacionais e do trabalho de seus trabalhadores.

\section{Referências}

Alves-Mazzoti, A. J., Gewandsznajder, F. (1999) O método nas ciências naturais e sociais. São Paulo: Thompson.

Bastos, A. V. B., Borges-Andrade, J. E. (1995) Comprometimento no trabalho: identificando padrões de comprometimento do trabalhador com a organização, a carreira e o sindicato. Anais do Encontro da ANPAD, João Pessoa, PB, Brasil, 19.

Borges, L. O. (1999) A estrutura fatorial dos atributos valorativos e descritivos do trabalho: um estudo empírico de aperfeiçoamento e validação de um questionário. Estudos de Psicologia, 4(1): 107-139. 
Campos, B. A. (2008) Estrutura de valores relativos ao trabalho: um estudo em empresas juniores. In: M. L. M. Teixeira (org.). Valores Humanos \& Gestão - novas perspectivas (pp. 389-408). São Paulo: Senac.

Collis, J., Hussey, R. (2005) Pesquisa em Administração. Porto Alegre: Bookman.

Dejours, C. (1988) A Loucura do Trabalho. São Paulo: Cortez.

Elizur, D. (1984) Facets of work values: a structural analysis of work outcomes. Journal of Applied Psychology, 69(3):379-389.

Elizur, D., Sagie, A. (1999) Facets of personal values: a structural analysis of life and work values. Applied Psychology, 48(1): 73-87.

Fleury, M. T. L. (1991) Cultura organizacional e estratégias de mudanças: recolocando estas questões no cenário brasileiro atual. Revista de Administração, 26(2):3-11.

Godoy, A. S. (1995) Introdução à pesquisa qualitativa e suas possibilidades. Revista de Administração de Empresas - RAE, 35(2):57-63.

Lüdke, M., André, M. E. D. A. (1986) Pesquisa em educação: abordagens qualitativas. São Paulo: EPU. Miles, M. B. (1979). Qualitative data as an attractive nuisance: the problem of analysis. Administrative Science Quarterly, 24(4):590-601.

Oliveira, A. F., Tamayo, A. (2004) Inventário de perfis de valores organizacionais. Revista de Administração de Empresas (USP), 39(2):129-140.

Porto, J. B. (2005) Mensuração de Valores no Brasil. In: A. Tamayo, J. B. Porto. Valores e comportamento nas organizações (pp. 96-119). Petrópolis, RJ: Vozes.

Porto, J. B., Tamayo, A. (2003) Escala de Valores Relativos ao Trabalho - EVT. Psicologia: Teoria e Pesquisa, 19(2):145-152.

Porto, J. B., Tamayo, A. (2008) Valores do Trabalho. In: M. M. M. Siqueira (org.). Medidas do Comportamento Organizacional: ferramentas de diagnóstico e de Gestão (pp. 295-307). Porto Alegre: Artmed.

Ros, M., Gouveia, V. V. (2006) Valores, atitudes e comportamento: uma nova visita a um tema clássico. M. Ros, V. V. Gouveia (orgs.) Psicologia social dos valores humanos: desenvolvimentos teóricos, metodológicos e aplicados (pp. 87-114). São Paulo: Senac.

Ros, M., Schwartz, S. H., Surkiss, S. (1999) Basic values, work values and the meaning of work. Applied Psychology: An International Review, 48(1):49-71.

Santos, S. W., Fischer, R., Milfont L. T., Gouveia, V. (2008) Teoria funcionalista dos valores humanos. In: M. L. M. Teixeira (org.). Valores humanos e gestão: Novas Perspectivas (pp. 47-80). São Paulo, SP: Senac.

Schwartz, S. H. (2005a) Valores Humanos básicos: seu contexto e estrutura intercultural. In: A. Tamayo, J. B. Porto (orgs.). Valores e comportamento nas organizações (pp. 21-55). Petrópolis, RJ: Vozes.

Schwartz, S. H. (2005b) Validade e aplicabilidade da Teoria de Valores. In: A. Tamayo, J. B. Porto (orgs.). Valores e comportamento nas organizações (pp. 56-95). Petrópolis, RJ: Vozes.

Super, D. E. (1957) The psychology of careers. New York: Harper \& Row.

Tamayo, A. (2005) Impacto dos valores pessoais e organizacionais sobre o comportamento organizacional. In: A. Tamayo, J. B. Porto. Valores e comportamento nas organizações (pp.160-186). Petrópolis, RJ: Vozes.

Tamayo, A. (2008) Valores Organizacionais. In: M. M. M. Siqueira (org). Medidas do Comportamento Organizacional: ferramentas de diagnóstico e de Gestão (pp. 309-340). Porto Alegre: Artmed.

Tamayo, A., Gondim, M. G. C. (1996) Escala de Valores Organizacionais. Revista de Administração, São Paulo, 31(2):62-72.

Tamayo, A., Mendes, A. M., Paz, M. G. T. (2000) Inventário de valores organizacionais. Estudos de Psicologia, 5(2):289-315.

Tardif, M. (2002) Saberes docentes e formação profissional. Petrópolis, RJ: Vozes. 
Teixeira, M. L. M. (2008) Dignidade organizacional: valores e relações com stakeholders. In: M. L. M. Teixeira (org.). Valores humanos e gestão: Novas Perspectivas (pp. 81-92). São Paulo, SP: Senac.

Triviños, A. N. S. (1987) Introdução à pesquisa em ciências sociais. São Paulo: Atlas.

Vergara, S. C. (2009) Projetos e relatórios de pesquisa em administração. São Paulo: Atlas.

Yin, R. K. (2001) Estudo de caso: planejamento e métodos. Porto Alegre: Bookman. 